\title{
STUDY OF PAPER MICROBIAL FUEL CELLS FOR USE IN ON-SITE WASTEWATER TESTING
}

\author{
A Thesis \\ presented to \\ the Faculty of California Polytechnic State University, \\ San Luis Obispo
}

\author{
In Partial Fulfillment \\ of the Requirements for the Degree \\ Master of Science in Biomedical Engineering
}

by

William Tolmasoff

June 2019 
(C) 2019

William Alexander Tolmasoff

ALL RIGHTS RESERVED 
TITLE: Study of Paper Microbial Fuel Cells for Use in On-Site Wastewater Testing

AUTHOR: William Alexander Tolmasoff

DATE SUBMITTED: June 2019

COMMITTEE CHAIR: $\quad$ David Clague, Ph.D

Professor of Biomedical Engineering

COMMITTEE MEMBER: Christopher Kitts, Ph.D

Professor of Biology

COMMITTEE MEMBER: Dr. Michael Whitt, Ph.D

Assistant Professor of Biomedical Engineering

COMMITTEE MEMBER: Jamey Eason, Ph.D

Lecturer of Biomedical Engineering 


\begin{abstract}
Study of Paper Microbial Fuel Cells for Use in On-Site Wastewater Testing William Alexander Tolmasoff
\end{abstract}

This study demonstrated a technique for fabricating simple, low-cost Paper Microbial fuel cells (PMFC's) in the model of a previous study to, for the first time, produce voltage from wastewater effluent. The PMFC's were created by stacking and gluing the main components of an MFC together: reservoir layer; anode; cation exchange membrane (CEM); air cathode. A wax printer was used to create the hydrophobic borders of the PMFC's on filter paper, and graphite paint was applied to the paper to create the anode. The CEM's considered were filter paper, wax, and Nafion, with Nafion being the most efficient. Finally, the air cathode was made using carbon veil, and leads (or resistors) were placed in both anode and cathode layers for voltage measurement. Confirming previous studies' results, the PMFC's had a rapid startup time and sustained voltage for at least 10 minutes. The study also found that: Nafion was the best CEM; painting one side of the anode had the highest voltage; higher surface area increased voltage; increased time from sampling decreased voltage. Thus, this study proved that the small, low-cost PMFC devices described in previous studies can produce a voltage using primary effluent, and showed that the surface area of the PMFC could be optimized to increase voltage.

Keywords: Paper Microbial Fuel Cells, Wastewater Quality Testing, Developing Nations 


\section{ACKNOWLEDGMENTS}

I would like to first thank Dr. Christopher Kitts for advising me over all these years, I couldn't have done it without him. Second, I would like to thank Dr. David Clague for his advice and help with my masters. Also, I would like to thank Drs. Whitt and Eason for stepping up last minute to join my thesis committee. Finally, I truly appreciate the funding that I received from the Baker-Koob Endowment, this project would not have been possible without the grant they gave me. 


\section{TABLE OF CONTENTS}

Page

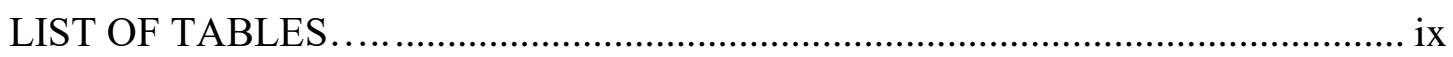

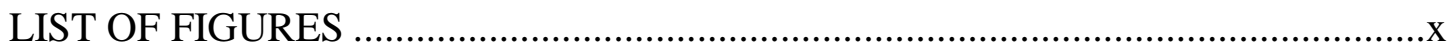

\section{CHAPTER}

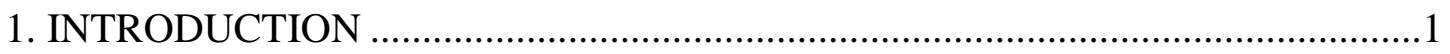

1.1 Water Quality in Developing Nations..........................................................

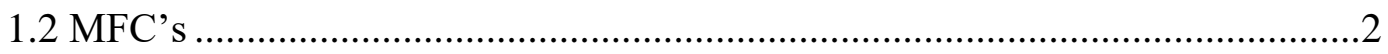

1.3 PMFC's

1.4 CEM's

1.5 Specific Goals of This Thesis Project and Report ...........................................8

1.6 Organization of the Remainder of the Report................................................

2. METHODS AND MATERIALS...................................................................10

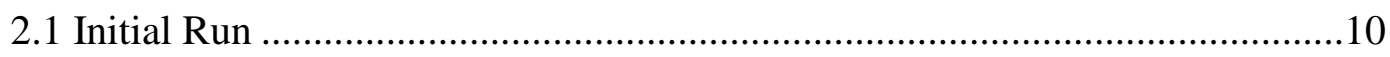

2.1.1 Overall Construction Method for Initial Run ........................................10

2.1.2 Geometry for Initial Run..................................................................10

2.1.3 Wax Printing for Initial Run ..............................................................12

2.1.4 Insertion Layer Manufacture for Initial Run ........................................13

2.1.5 Anode Layer Manufacture for Initial Run ............................................13

2.1.6 CEM Layer Manufacture for Initial Run ...............................................14

2.1.7 Cathode Layer Manufacture for Initial Run ..........................................16

2.1.8 Construction for Initial Run ...............................................................17

2.1.9 Initial Run Experimental Methods.....................................................18 


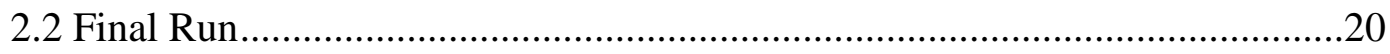

2.2.1 Overall Construction Method for Final Run .........................................20

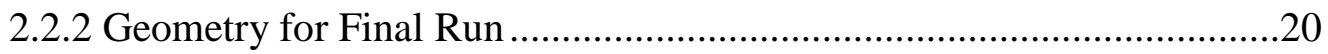

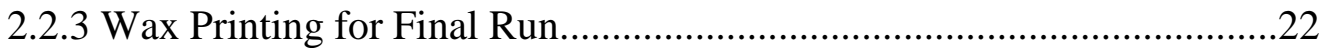

2.2.4 Insertion Layer Manufacture for Final Run .........................................22

2.2.5 Anode Layer Manufacture for Final Run............................................22

2.2.6 CEM Layer Manufacture for Final Run..................................................23

2.2.7 Cathode Layer Manufacture for Final Run ...........................................23

2.2.8 Construction for Final Run ................................................................23

2.2.9 Final Run Experimental Methods ………………..............................24

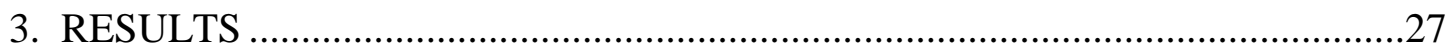

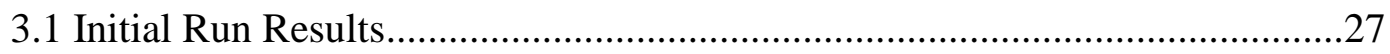

3.1.1 Initial Run Data Analysis ...................................................................2

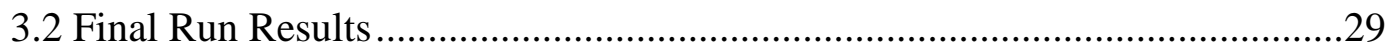

3.2.1 Final Run Data Analysis ......................................................................

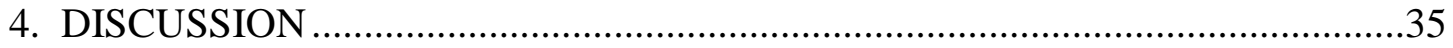

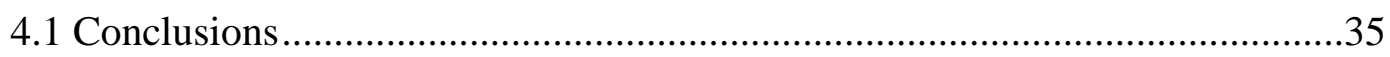

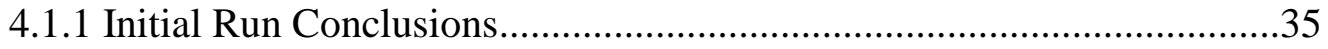

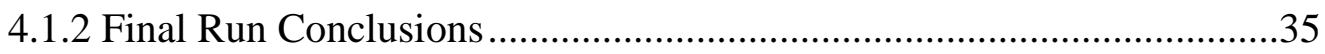

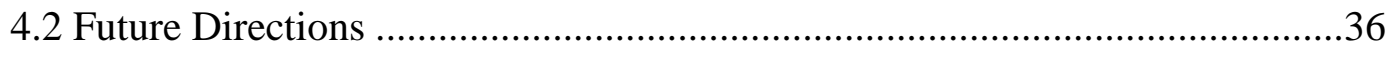

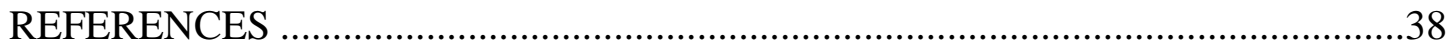

\section{APPENDICES}

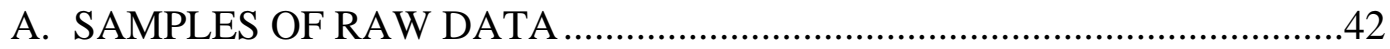




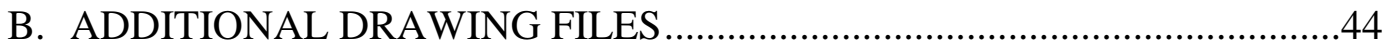

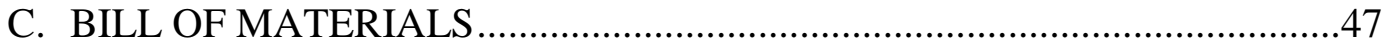




\section{LIST OF TABLES}

Table Page

1. Final Run's Randomized Trial with Center Points .......................................25

2. Predictions for the Effect of Usable Surface Area on Voltage ..........................34

3. Sample of Initial Run Raw Data .............................................................42

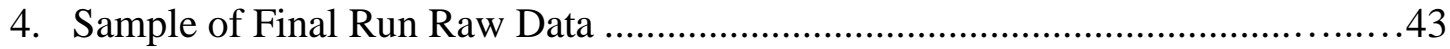

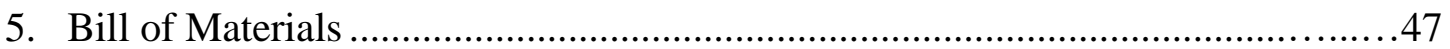




\section{LIST OF FIGURES}

Figure

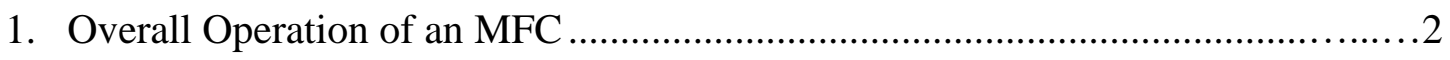

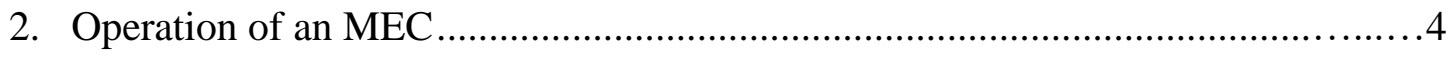

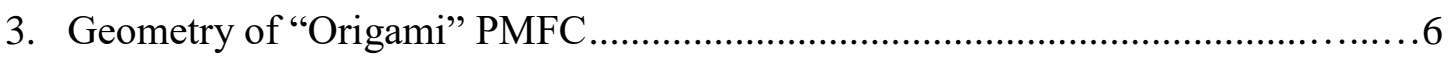

4. Overall Operation of the "Origami” PMFC ................................................

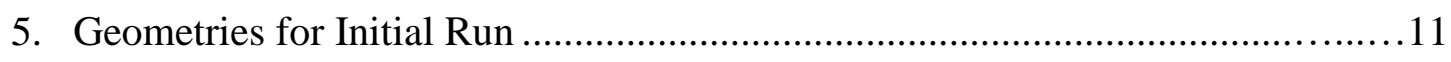

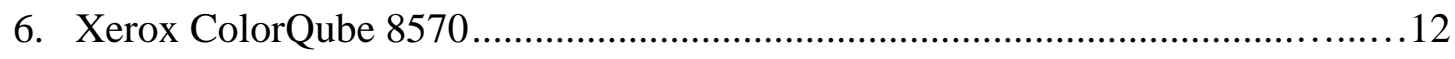

7. Insertion Layer with Center Hole …....................................................... 13

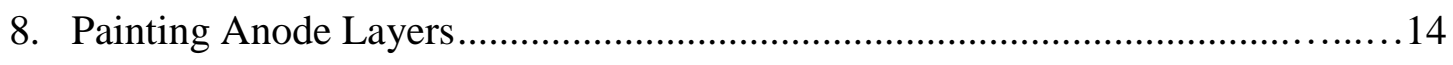

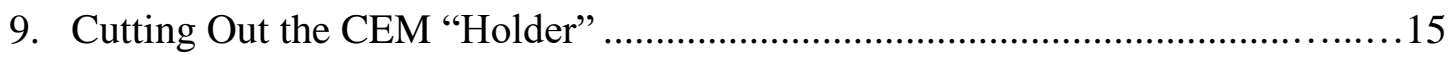

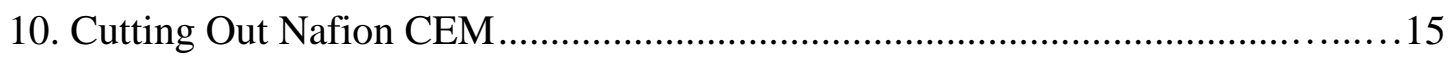

11. Cutting out Whatman \#410 CEM ........................................................... 16

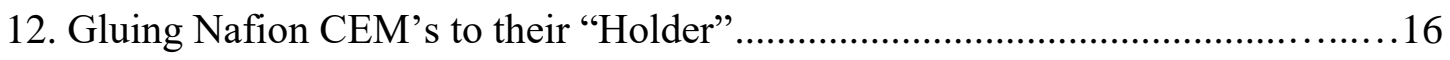

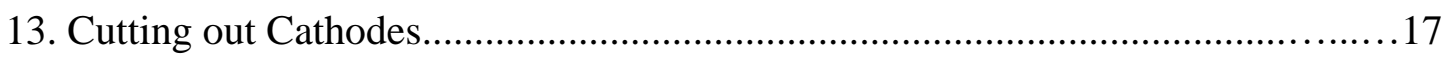

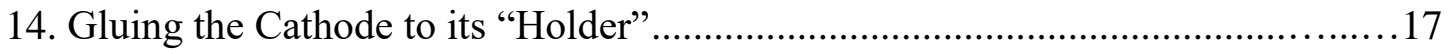

15. Completely Constructed PMFC's for Final Run ....................................... 18

16. Measurement Method for the First PMFC ..................................................... 19

17. Measurement Method for other PMFC's …................................................. 19

18. Insertion Point for Wastewater Effluent .................................................. 20

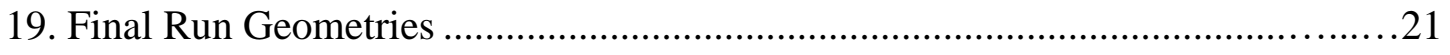

20. Insertion Layer Glued to Anode Layer .......................................................22

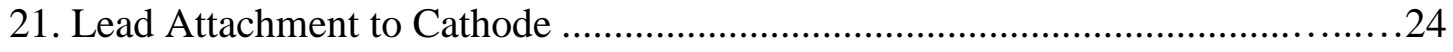


22. Completely Constructed PMFC's for Final Run

23. Experimental Setup for Final Run .26

24. ANOVA Results for Initial Run 27

25. Tukey Pairwise Comparisons for CEM Type 28

26. Tukey Pairwise Comparisons for Time …................................................28

27. Voltage Over Time for Initial Run. .29

28. Factorial Regression Results for Final Run ............................................... 30

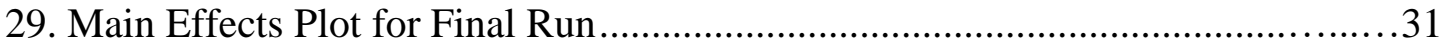

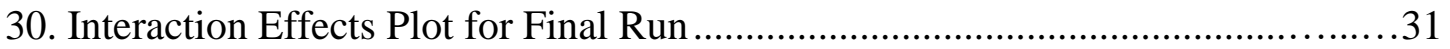

31. Average Voltage Over Time for Final Run ................................................ 33

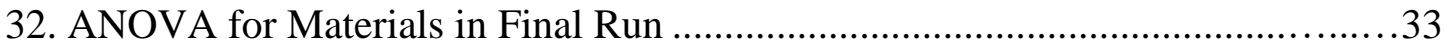

33. Tukey Pairwise Comparisons for Materials in Final Run.................................33

34. Overall Layout for Initial PMFC …..................................................... 44

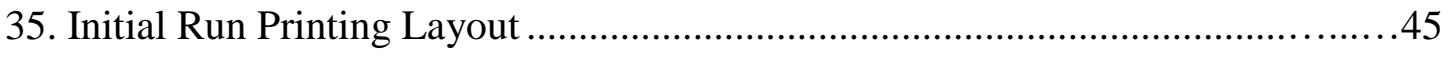

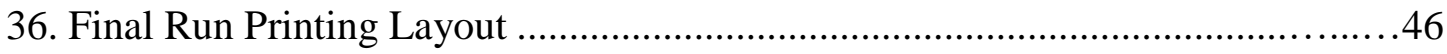




\section{Chapter 1}

\section{INTRODUCTION}

\subsection{Water Quality in Developing Nations}

Getting clean water is a huge burden for those in poverty, and getting said water is often very expensive or impossible $[1,2]$. Without access to clean water, many people in developing nations have to deal with chronic weakness and diarrhea, along with other more deadly diseases like cholera [3]. This can lead to loss of employment, education, and even life. 2.5 billion people throughout the world drink water that is untreated, and another 750 million live with water that is ineffectively treated [4]. In addition, up to 1.8 billion people drink water that is fecally contaminated [5].

Thus, clean water is important to economic growth and public health in developing countries [1]. A big part of ensuring that communities have clean water is water quality testing. In countries without highly developed infrastructure, water quality testing is difficult, if not impossible [1]. While water quality testing is common in developed nations, the tests (e.g. dissolved oxygen test) often relies on lab equipment that is expensive, difficult to operate, and not portable [6]. Also, some of the tests, such as biochemical oxygen demand (BOD), which is a common standard for wastewater quality that determines the level of organic pollution present in wastewater, are slow (5 days) and performed off site [7]. These qualities of current water quality tests make them almost entirely useless in a developing nation, where testing would require speed, portability, a low cost, and on-site capabilities [8]. Along with better sanitation and wastewater treatment, solving these aspects of wastewater testing would make a huge difference in 
ensuring water quality in developing nations [8]. A device that offers promise in this area is the microbial fuel cell (MFC).

\subsection{MFC's}

The MFC is a bioelectrochemical device that can use hydrogen carriers, usually in the form of organic compounds, to produce electricity from microbes under anaerobic conditions [9]. These microbes typically oxidize organic compounds in an anode chamber to produce electrons and protons. The electrons flow from the anode surface through an external circuit to the cathode chamber, while the protons diffuse through a cation exchange membrane (CEM) to the cathode chamber, creating water when they meet the electrons [9]. Thus, electrical flow is created between the cathode and anode, and the power output of the MFC can be captured and measured by a load, seen in figure 1 [10].

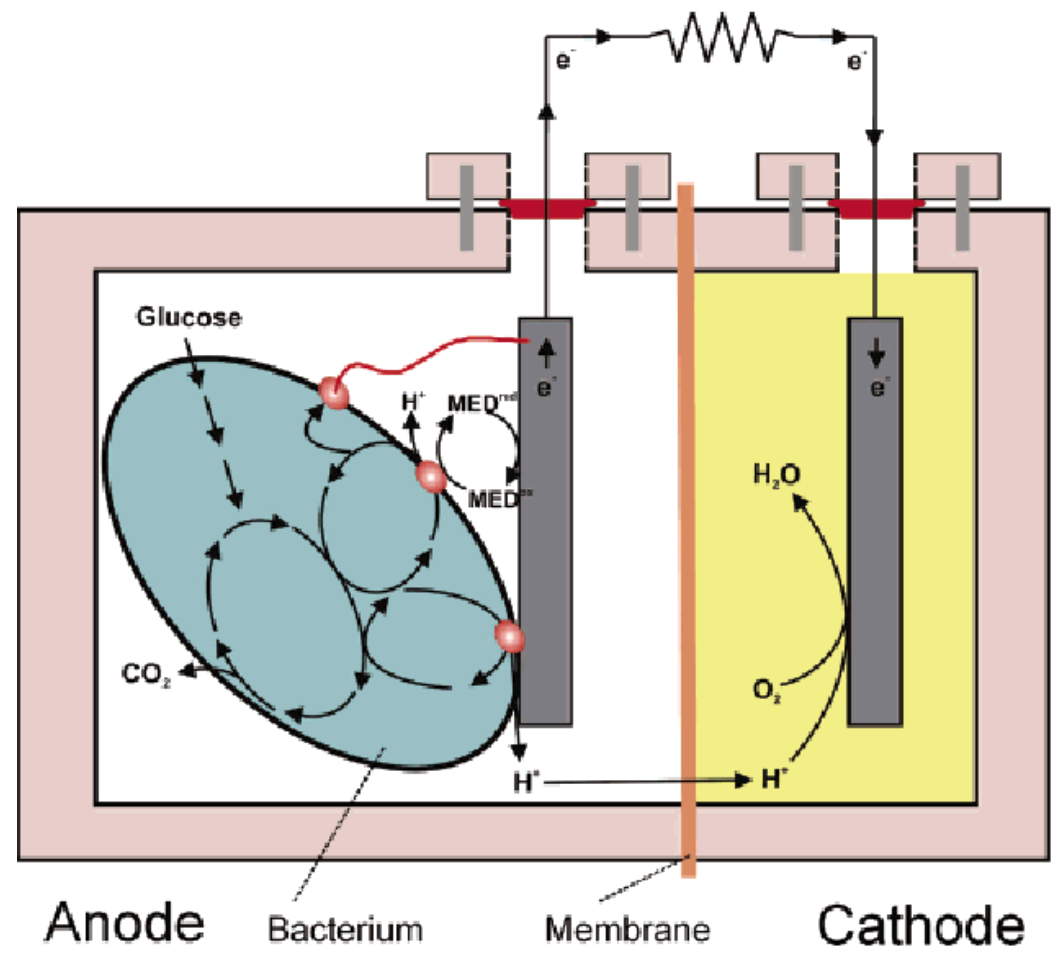

Figure 1: Overall Operation of an MFC [10] 
The history of the MFC really begins with the invention of the first battery, created by Alessandro Volta in the late $18^{\text {th }}$ century [10]. With numerous advances over the following century, the efficiency, power density, and cost of operating various chemical fuel cells vastly improved [10]. However, while chemical fuel cells like lithiumion batteries offer many advantages, they have disadvantages such as high operating temperatures and corrosive byproducts [10]. Thus, MFC's were explored as a concept to attenuate these disadvantages, since they have mild reactions and inexpensive electrolytes [10]. The concept of the MFC was first popularized in the 1960's by NASA, who sought at the time to use waste as energy during space missions [11]. The modern conception of the MFC however, is credited to the work of Benneto et al. in the late 80's and early 90's, who developed the "analytic MFC" that is still the base concept of MFC's today [11].

After the work of Benneto et al., the advancement of MFC's rapidly increased starting in the early 2000 's, leading to the creation of a number of important devices. One such device was the microbial electrolysis cell (MEC) [11]. As seen in figure 2, when a small electric current is applied to this device, it allows the bacteria to start producing hydrogen from organic materials [12]. This hydrogen can then be captured and used for various applications, such as hydrogen fuel cells. 


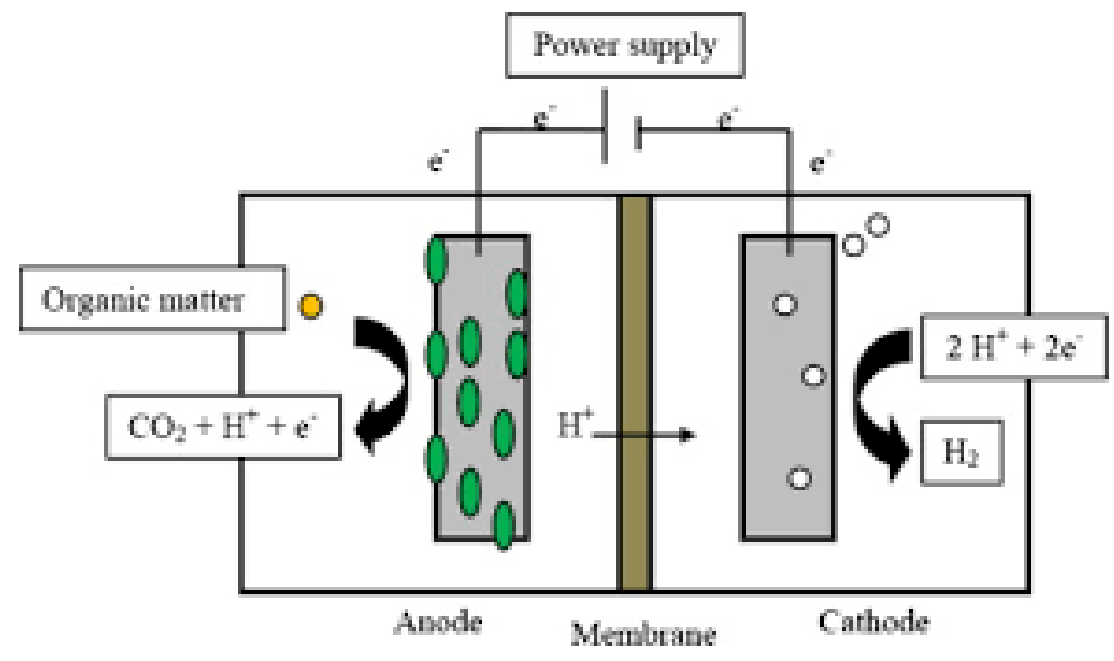

Figure 2: Operation of an MEC [10]

Other MFC's are used to produce power directly, such as the microfluidic fuel cell of Kamitani et al [13]. These devices tend to use organic electrolytes such as wastewater, and use specialized materials (e.g. activated carbon graphite ink, platinum electrodes) to produce capturable amounts of power. No matter what the size, MFC's have a maximum theoretical voltage of $1.1 \mathrm{~V}$ however, since this is the maximum organic oxidation potential possible (between oxygen and acetate) [14]. Thus, most real world applications tend to put together many smaller MFC's in what is called a "stack." Stacks put the smaller MFC's into parallel and series configurations that allow the stack to achieve higher voltages and currents than one MFC of an equal size could produce [14]. Sometimes MFC's will experience an initial negative voltage due to reversed polarity, which is caused by fluid flux and imbalances in the MFC's microbial cascades [15].

Much work has been put into using MFC's as a power source, but a number of limitations, including lack of understanding of electrogenic microbial activity, the low maximum voltage possible, and low power density, have made MFC's as a power source seem unlikely in the near future [15]. However, their ability to create power based on 
microbes' metabolic activity allows them to be used as sensors, since disturbances to microbial metabolism, such as environmental changes or the presence of pollutants, cause a measurable difference in the measured voltage of the MFC [15]. In fact, MFC based biosensors have been used to test for a variety of industrial wastewater contaminants, such as chromium, iron, nitrate, and sodium acetate [16, 17]. In addition, MFC biosensors can detect aspects of wastewater quality like biochemical oxygen demand (BOD) [18]. The advantage of MFC's over other methods of water quality testing is their simplicity, as there isn't any need for external equipment to act as a transducer - the anode itself is the transducer [19].

Even though MFC's hold promise as water quality biosensors, many designs are not practical for use in poor regions of the world due to their expensive materials and low portability [9]. To solve these problems and increase MFC biosensors' utility in developing countries, paper electronics has been suggested as a solution [8].

\subsection{PMFC's}

Paper electronics is the concept of using paper as a functional part of a device, and allows for the creation of cheap, light, and potentially recyclable electronics [20]. Incorporating paper into the design of an MFC makes it a paper microbial fuel cell, or PMFC. Important advantages of the PMFC are that it has an exponentially lower start up time and is usually much lower cost than traditional MFC's [21, 22]. The reason for this low start up time is that the paper in the PMCF acts to pull liquid through the device due to flux across the CEM. This basically means that the paper helps "suck up" the fluid through the device in order to help the PMFC produce voltage more quickly. In addition, by using printed hydrophobic wax for fluid retention and screen printing cathode and 
anode materials, construction time can be significantly decreased [23]. This thesis largely draws from such a device, specifically an "origami" PMFC designed by the Choi et al., as seen in figure 3 below [24].

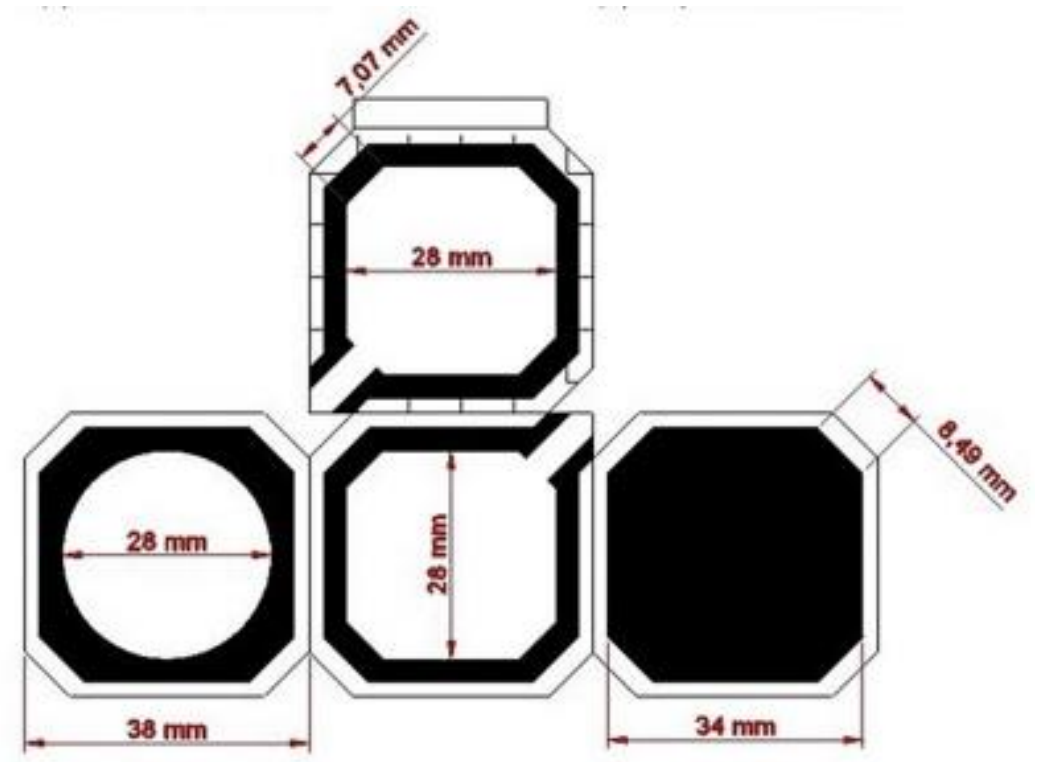

Figure 3: Geometry of "Origami” PMFC [24]

The origami PMFC shown above had four layers: (1) insertion/reservoir layer (left layer); (2) anode layer (top layer); (3) CEM (right layer); (4) air cathode (middle layer) [15]. These layers were then folded together to create a 3D PMFC device, as seen in figure 4 below. The device used an inoculum of specialized electrogenic bacteria, Shewanella oneidensis, with artificial wastewater for fuel, and was able to produce up to $.4 \mathrm{~V}$ using graphite ink as the anode material [24]. The top/reservoir layer was used to retain the organic materials for increased device run time. It also had a specialized air cathode that used activated carbon catalysts in a carbon spray along with Nafion solution [24]. 


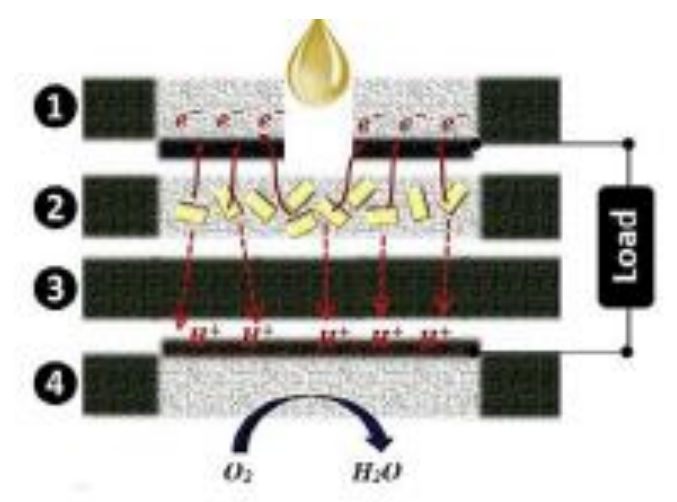

Figure 4: Overall Operation of the "Origami” PMFC [24]

While this device was impressive in its construction method and small size, it was not very practical in the real world, especially in developing nations. For one, using a pure culture would never be possible in the world of wastewater quality testing, which was the ultimate goal of the "origami” PMFC. In addition, it used difficult construction techniques and expensive materials to create the cathodes and anodes, further reducing its practicality in developing nations.

\subsection{CEM's}

CEM's are the part of the PMFC that allow protons to pass from the anode chamber, where they are released by organic molecule oxidation, to the cathode chamber, where they join with electrons to form water [25]. For most fuel cells, CEM's tend to be a polymer film that have a hydrophobic chain and hydrophilic side groups and have pores that allow for ion transfer [25].

One important quality of CEM's is their conductivity, which determines the proton transfer efficiency, i.e. as conductivity increases, so does the transfer of protons [25]. Conductivity can be tuned by choosing a CEM material with high conductivity (e.g. Nafion), or by doping the membrane with various substances like proton-generating materials or solid electrolytes. Furthermore, a CEM's conductivity can be optimized 
based on temperature and humidity, since these operating conditions can have a large effect on the proton transport rate based on the material. It should be noted that CEM's experience "swelling," where the fluid that is produced by the cathode is absorbed by the CEM, causing it to swell. However, there have not been in-depth studies that examine how this swelling affects the pore size and/or overall performance of the CEM [25]. In the "origami" PMFC, the device used two different types of CEM: (1) Nafion; (2) Wax [24]. Nafion was used because it is a commonly used CEM material in both research and commercial applications due to its high conductivity, even though it is relatively expensive [24]. They also tested printable wax as a CEM because it would greatly decrease manufacturing time, difficulty, and cost, and wanted to learn how well it worked compared to the industry standard (Nafion). Another study used Whatman paper \#410 as a CEM, because it allows for a quick start up time and is a very low cost CEM material [22]. Because these materials had all been used in previous studies, these were the three CEM's that were used in this thesis.

\subsection{Specific Goals of This Thesis Project and Report}

In order to improve upon the "origami" PMFC, the above impracticalities had to be addressed. Thus, the general purpose of this thesis project and report was to create a lower-cost, easier to construct PMFC that used wastewater effluent as its fuel source in the model of the "origami" PMFC. Furthermore, different materials and geometries were to be tested in order to determine the effect of these factors on PMFC voltage. The ultimate goal of this research is to pave the way for future research into PMFC's as water quality testing devices in developing nations. By the end of the study, the optimal CEM 
material, the effect of surface area on voltage, and how anode painting affects voltage will be revealed. This will be achieved by laying out in this thesis paper:

- An initial device design

- Initial experimental runs to:

○ Determine if the devices worked

- Investigate the best performing CEM material

- A final device design:

○ Improved on "origami" PMFC by making it:

- Less expensive

- Simpler to construct

- Final experimental runs to optimize voltage based on the following factors:

- Surface area

- Number of anode sides painted

○ Time from sample

- Material used to inoculate the PMFC

1.6 Organization of the Remainder of the Report

The remainder of the report consists of the following sections: (1) methods and materials; (2) results; (3) discussion; (4) appendices. Methods and materials will cover the construction of the PMFC's as well as the methods used to run the initial and final runs. The results cover the data and data analysis of the initial and final runs. The discussion is where the data analysis was used to draw conclusions about the PMFC's as well as determine future directions for research. Finally, the appendices cover samples of raw data, AutoCAD drawing samples, and a bill of materials. 


\section{Chapter 2}

\section{METHODS AND MATERIALS}

\subsection{Initial Run}

\subsubsection{Overall Construction Method for Initial Run}

A thumbnail description of the overall construction process for the initial run is as follows:

(1) Cutting filter paper to size and printing wax on filter paper

(2) Cutting out printed pieces, cathodes, and CEM's

(3) Painting anodes with conductive paint

(4) Gluing CEM's and Cathodes to their "holders"

(5) Gluing all the pieces together with a resistor

\subsubsection{Geometry for Initial Run}

For the first run, I essentially replicated the geometry of the "origami” PMFC, which was a $38 \mathrm{~mm}$ by $38 \mathrm{~mm}$ square with a $5 \mathrm{~mm}$ wax border for liquid retention (see figure 5 below). However, I tested 3 different CEM materials, which were: (1) wax; (2) Nafion; (3) Whatman Paper \#410. A resistor was used in this design in order to measure the power output of the PMFC. 

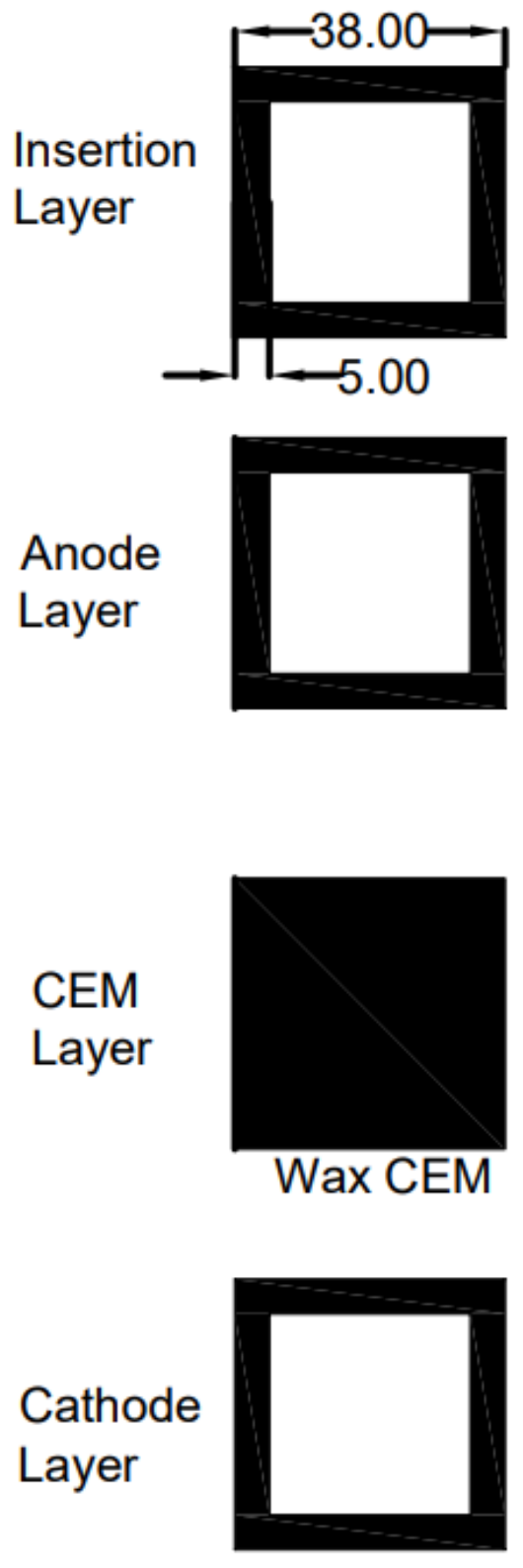

Figure 5: Geometries for Initial Run

\section{Note: Solid hatching represents where ink was printed}

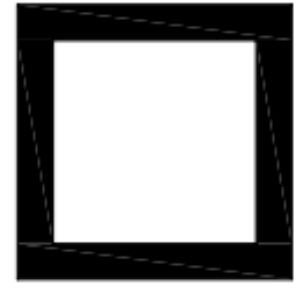

Nafion CEM

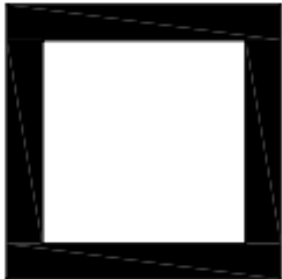

Whatman

Paper \#410 CEM

All models were created using AutoCAD, and were designed to be printed on 8.5 " by 11 " paper. Note here that the wax CEM used was a single layer of filter paper, since the CEM material was printed directly on the paper. 


\subsubsection{Wax Printing for Initial Run}

The base paper used for printing was Whatman Filter Paper \#1. The Whatman Paper was obtained in $600 \mathrm{~mm}$ by $600 \mathrm{~mm}$ sheets, and then cut down to four 8.5 " by 11 " sheets. The printing for the initial run was performed on a Xerox ColorQube 8570 (pictured below in figure 6), and printing was performed directly from AutoCAD. The first run involved creating 3 MFC's with each type of CEM, so 9 total MFC's were created from 36 total printed pieces. 20 PMFC pieces could be printed on each sheet of paper, so 2 sheets of paper were required for the 36 individual pieces.

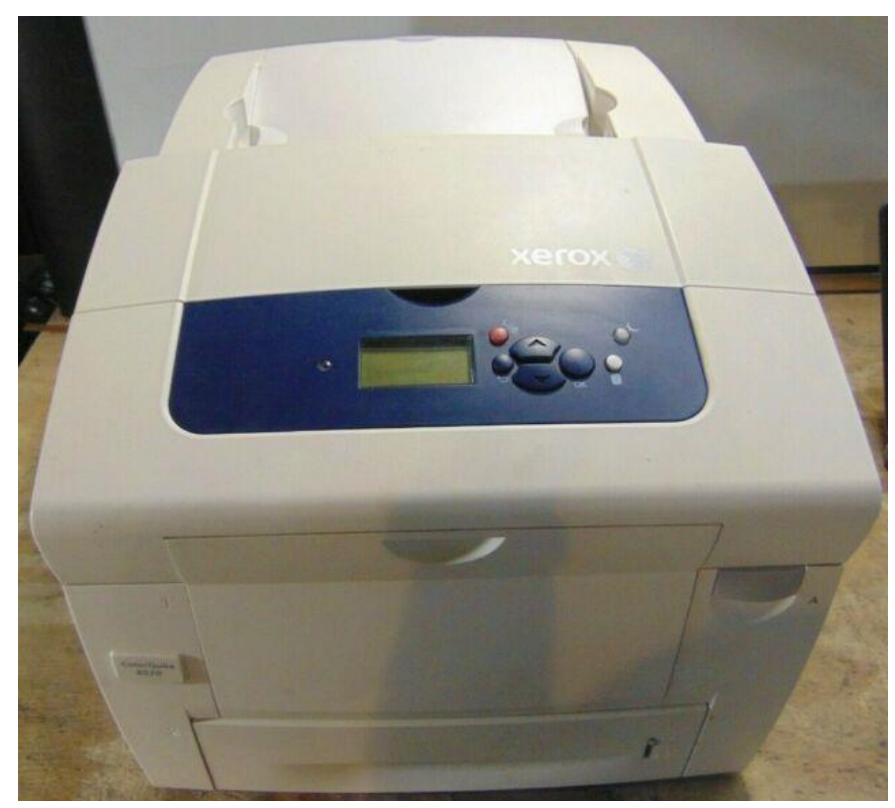

Figure 6: Xerox ColorQube 8570

The printer in Figure 6 is a standard printer that might be used in an office, but is able to use wax ink (also known as solid ink). This, coupled with AutoCAD, lowers the difficulty and time required for device construction. 


\subsubsection{Insertion Layer Manufacture for Initial Run}

The insertion layer was created by first cutting out the insertion layers. Then the insertion layers were folded in half so that a square could be cut out of the center, as shown below in figure 7 .

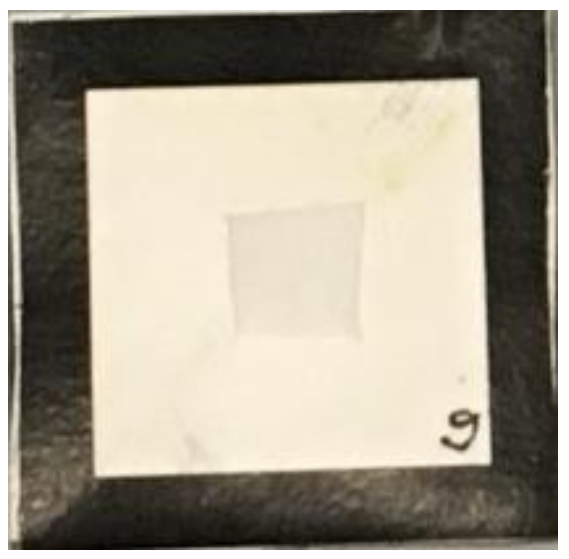

Figure 7: Insertion Layer with Center Hole

The middle cut out allows for fluid to come in direct contact with anode layer, while the rest of the insertion layer is able to retain the effluent that fuels the device.

\subsubsection{Anode Layer Manufacture for Initial Run}

The anode layer was created by first cutting out the printed anode layers. Then the layers were painted using a conductive graphite paint, as seen below in figure 8 . Finally, the insertion layer was glued to the anode layer, on the side opposite the conductive paint. This ensured that the anode surface came in direct contact with the CEM, maximizing electrical output. 


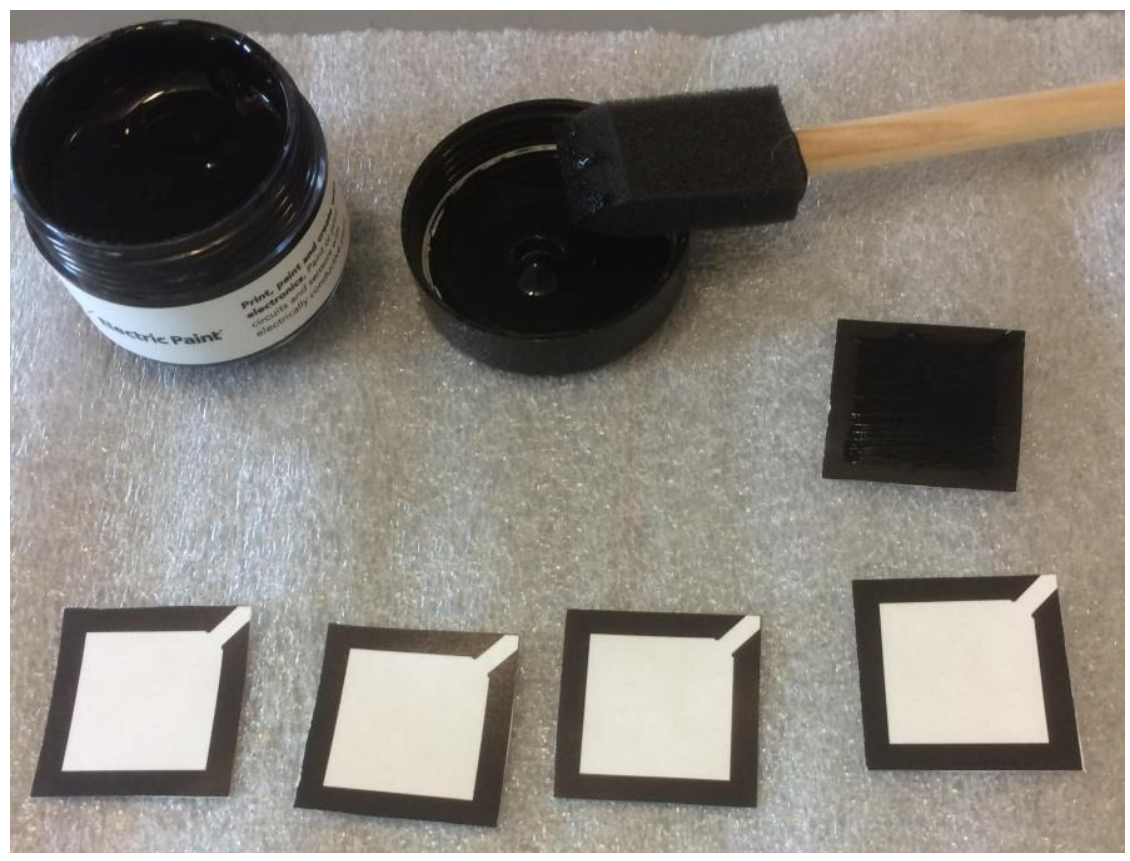

Figure 8: Painting Anode Layers

The conductive paint had a conductivity of $.05 \mathrm{~S} / \mathrm{m}$, which is about as conductive as tap water [26, 27]. Additionally, a sponge tipped brush was used to apply the conductive paint to the anode layer, and ensured sufficient precision and penetration of the paint.

\subsubsection{CEM Layer Manufacture for Initial Run}

First, the CEM layers were cut out from the printed filter paper. Then the squares were folded in half and the middle of the paper was cut out as shown below in figure 9 to create the CEM "holders." The wax CEM layers did not have their center cut out. 


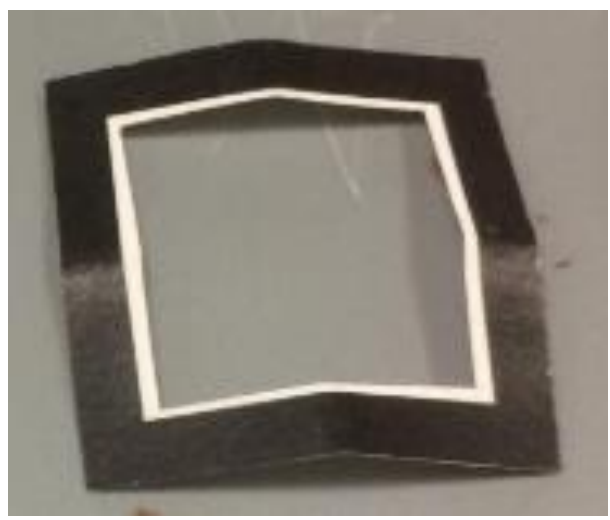

Figure 9: Cutting Out the CEM "Holder"

Note that the "holder" above has the white ring not by design, but because the "holder" was cut to have some extra paper, since the walls were so thin. Next, the CEM's themselves were cut out. The CEM's were cut to be $33 \mathrm{~mm}$ by $33 \mathrm{~mm}$, allowing for 2.5 mm of overlap with the "holder" on each side. The Nafion 115 came in $30 \mathrm{~cm}$ by $30 \mathrm{~cm}$ sheets and the Whatman Paper \#410 came on $12.5 \mathrm{~cm}$ diameter disks, so they had to be cut down to size, as shown below in figures 10 and 11. Finally, the Nafion and Whatman Paper CEM's were glued to their CEM holders, as seen in figure 12.

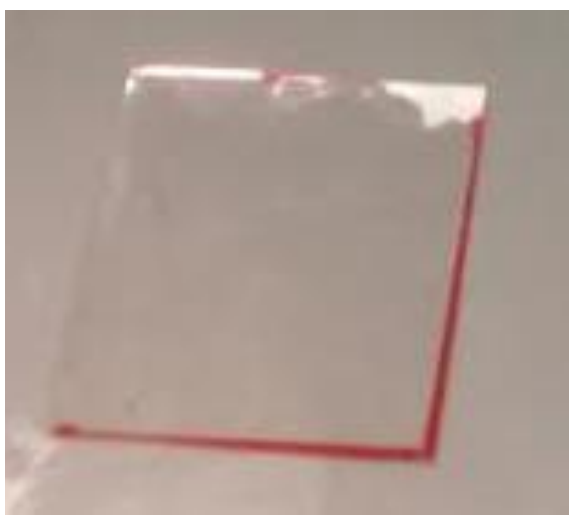

Figure 10: Cutting Out Nafion CEM 


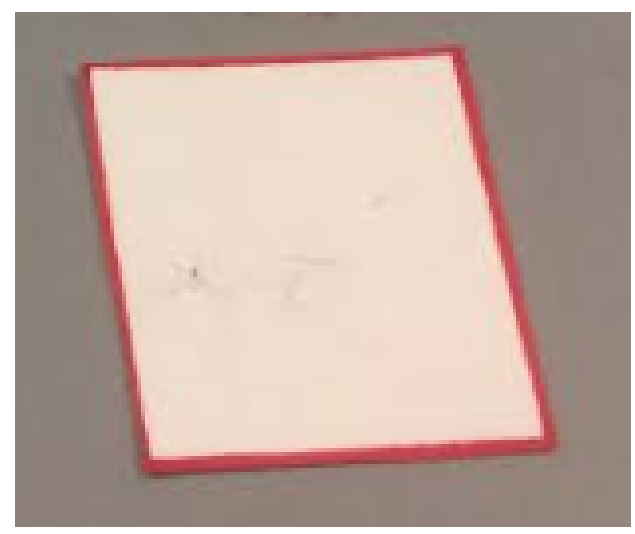

Figure 11: Cutting out Whatman \#410 CEM

Note that in figures 10 and 11 above, the red outline is simply from the sharpie that was used to mark the dimensions of the PMFC layers. A standard yard stick was used to measure out the CEM layers.

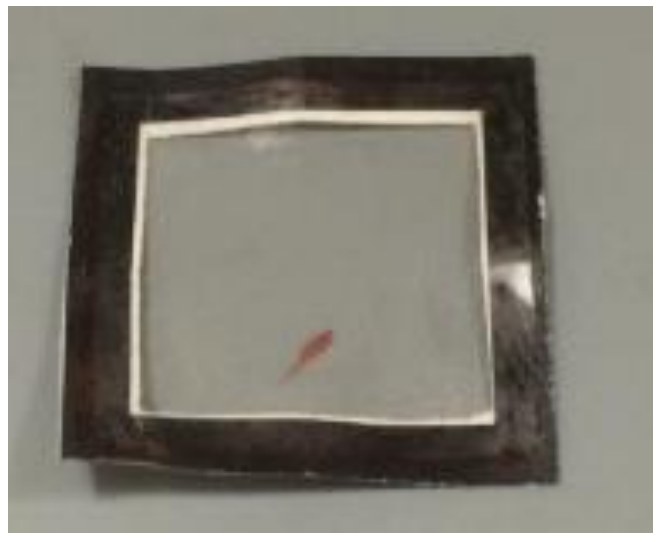

Figure 12: Gluing Nafion CEM's to their "Holder"

The orientation of the CEM layer did not matter when gluing, i.e. it did not matter which side of the CEM layer was glued to its "holder." However, the CEM was always glued to the side of its "holder" that had hydrophobic wax printed on it.

\subsubsection{Cathode Layer Manufacture for Initial Run}

First, cathode "holders" were cut out, and the middle sections cut out in the same way as the CEM "holders." The cathode material, carbon veil, came in 8.5 " by 11 " sheets 
so it had to be cut to size in order to be used as a cathode, as seen below in figure 13.

Then, the cathode was glued to the cathode holder as seen in figures 13 and 14.

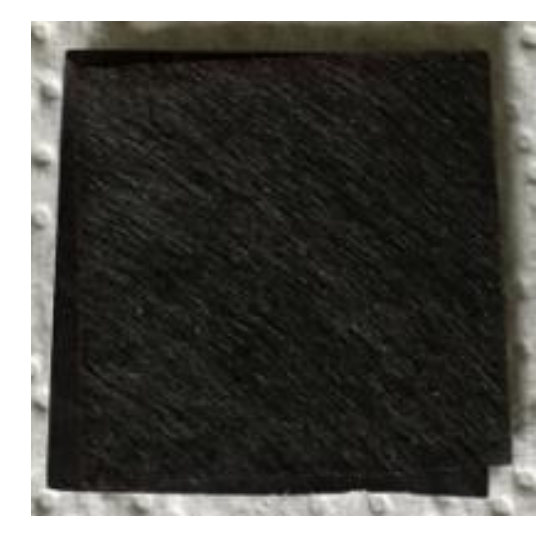

Figure 13: Cutting out Cathodes

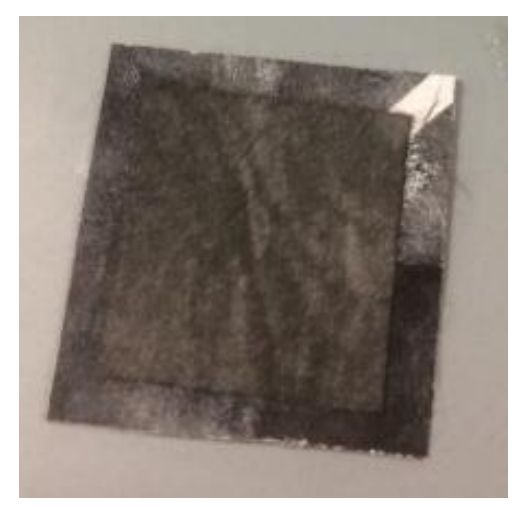

Figure 14: Gluing the Cathode to its "Holder"

The carbon veil had a weight of $40 \mathrm{~g} / \mathrm{m}^{2}$ and a conductivity of $.03 \mathrm{~S} / \mathrm{m}$, which is also about as conductive as tap water $[26,27]$. Note that the carbon veil was glued to the side of the "holder" that had hydrophobic wax printed on it. A yard stick was also used to measure the cathode layers.

\subsubsection{Construction for Initial Run}

Once the glue had dried for the pieces above, it was time to glue the $500 \mathrm{Ohm}$ resistor in between the necessary layers. A 500 Ohm resistor was used because: (1) it was in the range of resistance suggested in previous studies; resistors are needed to measure 
power output of an MFC; (3) having a resistance between the anode and cathode can help with MFC startup [11, 24]. The resistor had two be glued between three different layers: (1) between the anode and CEM; (2) between the cathode and CEM. This was performed by placing $3 / 4$ of a leg of the resistor on top of the CEM, and then gluing the anode on top. Then, the other leg of the resistor was placed underneath the CEM layer, and the cathode and its holder were glued underneath the CEM. This resulted in all layers being glued together into a single PMFC device as seen in figure 15.

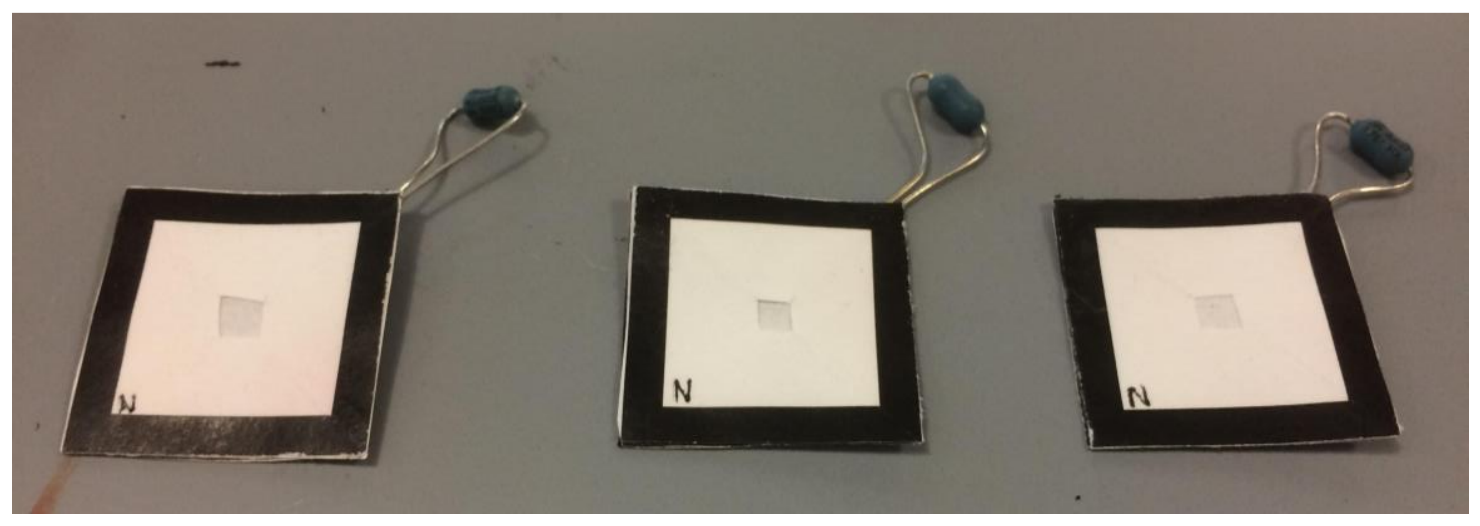

Figure 15: Completely Constructed PMFC's for Initial Run

As seen above, the legs of the resistor are situated very closely, so it is important in this step to make sure that the legs do not touch. If the legs were to touch, the circuit would short and no voltage would be created. Note that in the figure above, all PMFC's shown were made with a Nafion CEM.

\subsubsection{Initial Run Experimental Methods}

The initial run tested each of the 9 PMFC's for 5 minutes each. Wastewater effluent was obtained roughly four hours before testing began in order to ensure sample freshness. A voltmeter with probes was used for voltage measurement, and a phone timer was used to mark time from effluent insertion. The order of the testing was randomized, and for each PMFC, voltage was recorded every 30 seconds after effluent was inserted. 
Recordings were entered by hand into a notebook. All tests were performed inside a fume hood for smell control. For the first PMFC tested, voltage was recorded across the resistor using the voltmeter probes, as shown by the arrows in figure 16 .

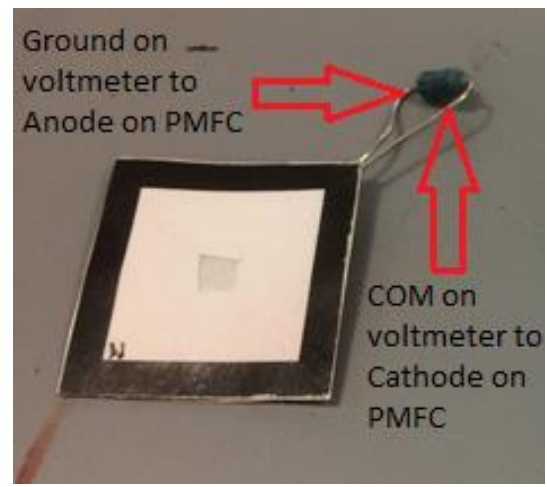

Figure 16: Measurement Method for the First PMFC

However, after obtaining $0 \mathrm{~V}$ readings, it was determined that the rest of the PMFC's should have their open circuit voltage (OCV) measured so that actual readings could be obtained. OCV was the metric used in the "origami" PMFC, so it was decided that OCV should also be measured in this study [24]. In addition, previous studies found a linear correlation between the OCV and BOD in biosensors, which was the ultimate goal of this research, and thus OCV seemed like a good metric to track [16]. This meant that the measurement method with the probes changed to measure between the cathode side of the resistor and the anode surface directly, as shown by the arrows in figure 17.

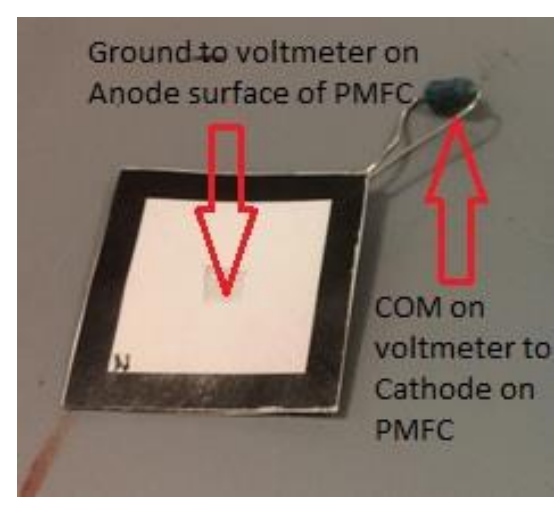

Figure 17: Measurement Method for other PMFC's 


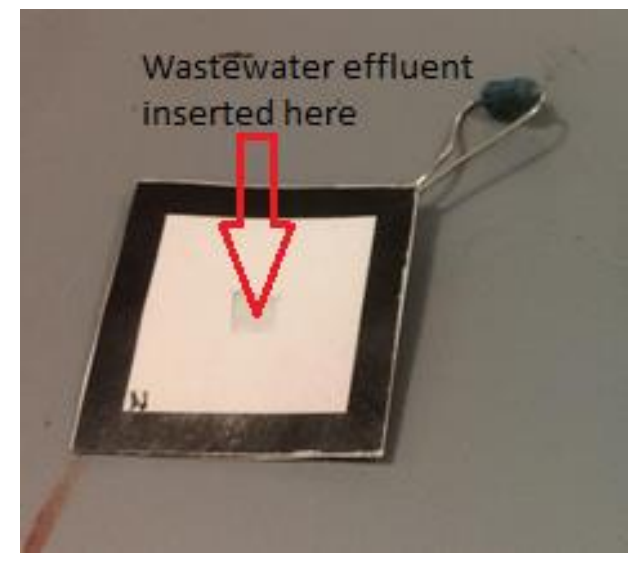

Figure 18: Insertion Point for Wastewater Effluent

Effluent was inserted in the middle cutout of the insertion layer (see figure 18 above), and $5 \mathrm{ml}$ were inserted into each PMFC using a plastic dropper. Note that the dropper was pressed directly onto the anode surface, and then squeezed to actively push the effluent through the device.

\subsection{Final Run}

\subsubsection{Overall Construction Method for Final Run}

The overall construction process for the final run was the same as the initial run's, except for: (1) some anodes had one or two sides painted with conductive paint; (2) no resistors were inserted between the layers, only wire leads. Wire leads were used instead of a resistor in order to measure $\mathrm{OCV}$, since during the initial run, measuring across the resistor yielded $0 \mathrm{~V}$.

\subsubsection{Geometry for Final Run}

For the final run, I used the same basic layout for the PMFC layers as the initial run. However, I tested three different PMFC sizes this time (see figure 19), which were: (1) $33 \mathrm{~mm}$ by $33 \mathrm{~mm}$; (2) $38 \mathrm{~mm}$ by $38 \mathrm{~mm}$; (3) $43 \mathrm{~mm}$ by $43 \mathrm{~mm}$. 

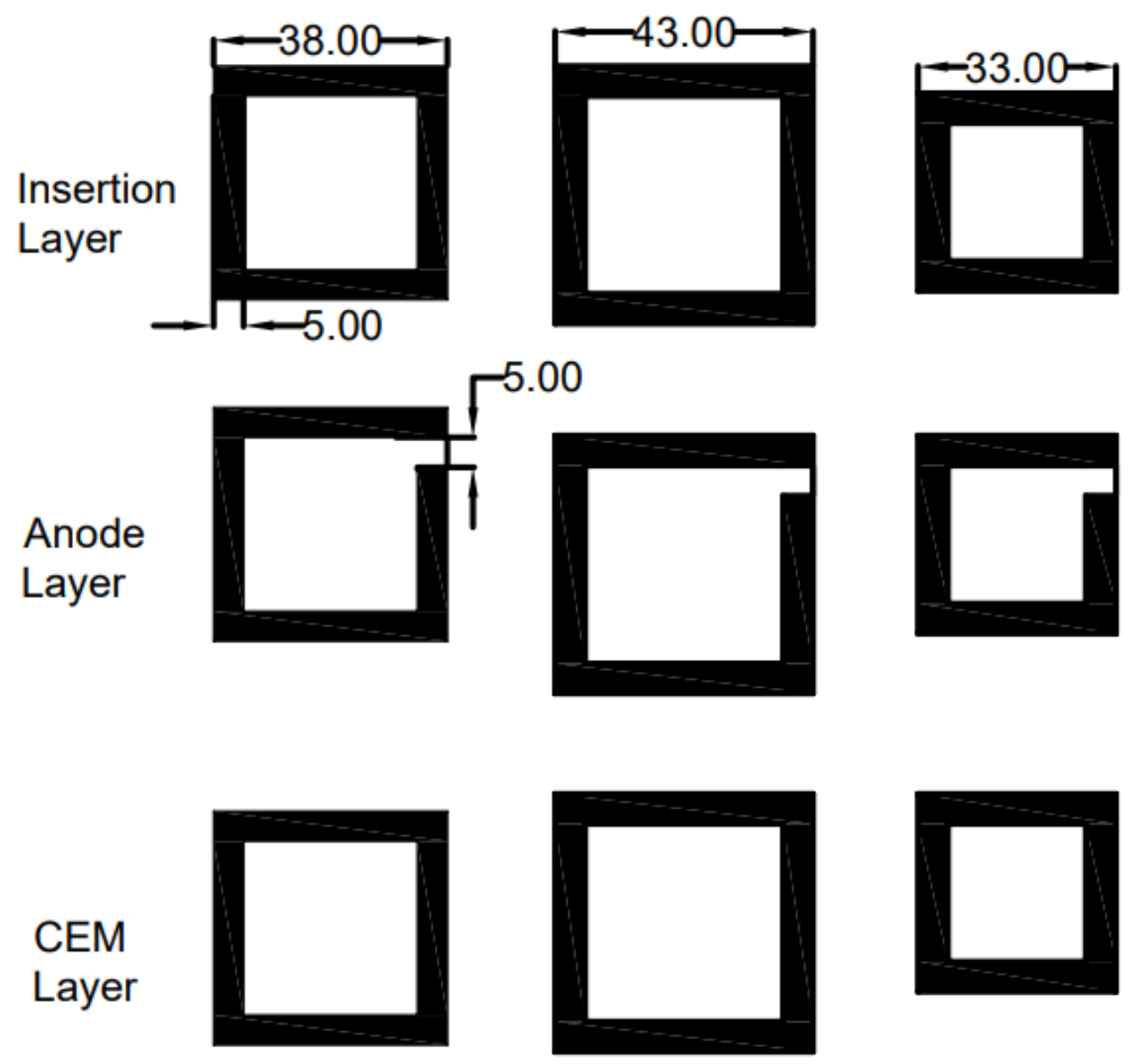

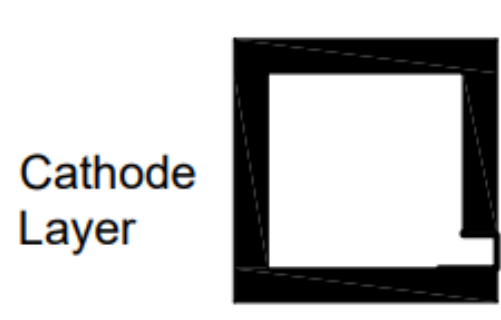

$38 \mathrm{~mm}$

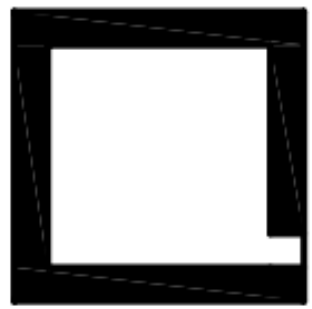

$43 \mathrm{~mm}$

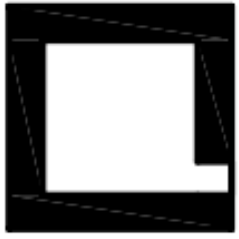

$33 \mathrm{~mm}$

Figure 19: Final Run Geometries

An important aspect of the models above is that the slot that allowed for conduction was moved to a more convenient location for construction and measurement, as seen above. 


\subsubsection{Wax Printing for Final Run}

The final run again used Whatman Paper \#1 as the base paper for printing, and the Xerox ColorQube 8570 printer was again used for printing. The final run involved creating 6 PMFC's with each of the 3 different geometries, so 18 total PMFC's were created from 72 total printed pieces, requiring four sheets of filter paper.

\subsubsection{Insertion Layer Manufacture for Final Run}

The insertion layers were created with the same method as the initial run.

\subsubsection{Anode Layer Manufacture for Final Run}

The anode layers were first cut out and then painted with conductive paint as in the initial run. The only difference was that this time, three PMFC's of each geometry had both sides of the anode painted, and the other three PMFC's of each geometry had only one side painted. The reason for painting one or two sides of the anode was that the “origami” PMFC used screen printing, which ensured full penetration of the anode material into the paper. However, in this study the anode material was painted on, so it was important to see if the device's performance was negatively affected by just painting one side of anode, which might not ensure full penetration of the graphite paint. Finally, the insertion layer was glued to the anode layer, on the side opposite the printed wax, as seen below in figure 20 .

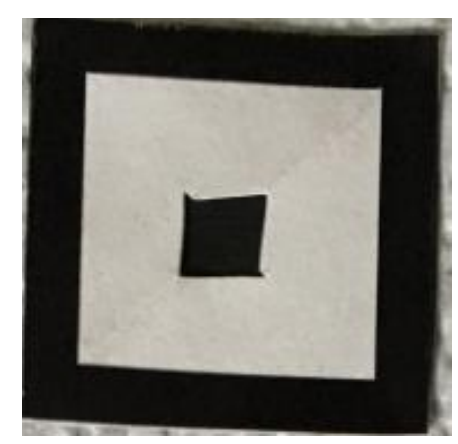

Figure 20: Insertion Layer Glued to Anode Layer 
Note that in the figure above, you can visually tell the anode is painted on both sides, since the conductive ink is visible through the insertion hole.

\subsubsection{CEM Layer Manufacture for Final Run}

First, the CEM "holders" were cut out in the same way as the initial run. Next, the CEM's themselves were cut out. The CEM's were cut to have $2.5 \mathrm{~mm}$ of overlap with the "holder" on each side, giving three different CEM geometries: (1) $28 \mathrm{~mm}$ by $28 \mathrm{~mm}$; (2) $33 \mathrm{~mm}$ by $33 \mathrm{~mm}$; (3) $38 \mathrm{~mm}$ by $38 \mathrm{~mm}$. After the Nafion was cut down to size, CEM's were glued to their "holders."

\subsubsection{Cathode Layer Manufacture for Final Run}

First, the cathode "holders" were cut out in the same way as the initial run. The carbon veil was cut down to the same geometries as the CEM's. Then, the cathodes were glued to the cathode "holders" as in the initial run.

\subsubsection{Construction for Final Run}

Once the glue had dried for the pieces above, the leads had to be glued in between the necessary layers: (1) between the anode and CEM; (2) between the cathode and CEM. The leads were created by cutting out and stripping the ends of three different lengths of wires: $40 \mathrm{~mm} ; 45 \mathrm{~mm} ; 50 \mathrm{~mm}$. Then, the first lead was placed on top of the cathode layer, and the CEM was glued on top of the cathode, as seen below in figure 21. Next, the other lead was placed on top of the CEM layer, and the anode/insertion layers were glued on top, resulting in a completed PMFC as seen in figure 22 below. 


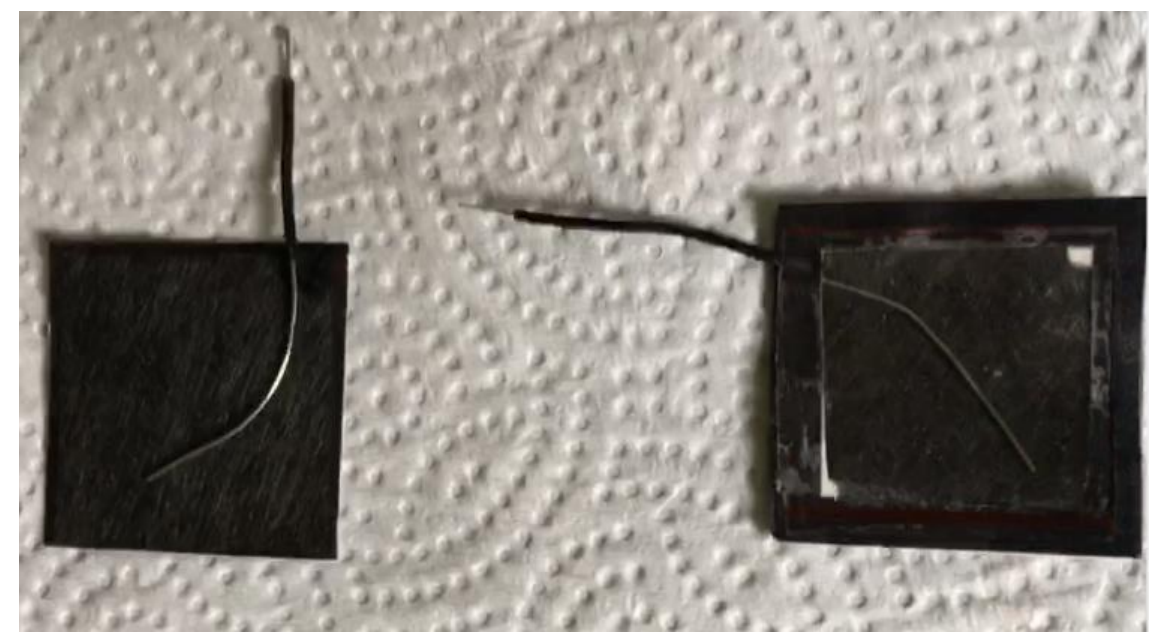

Figure 21: Lead Attachment to Cathode

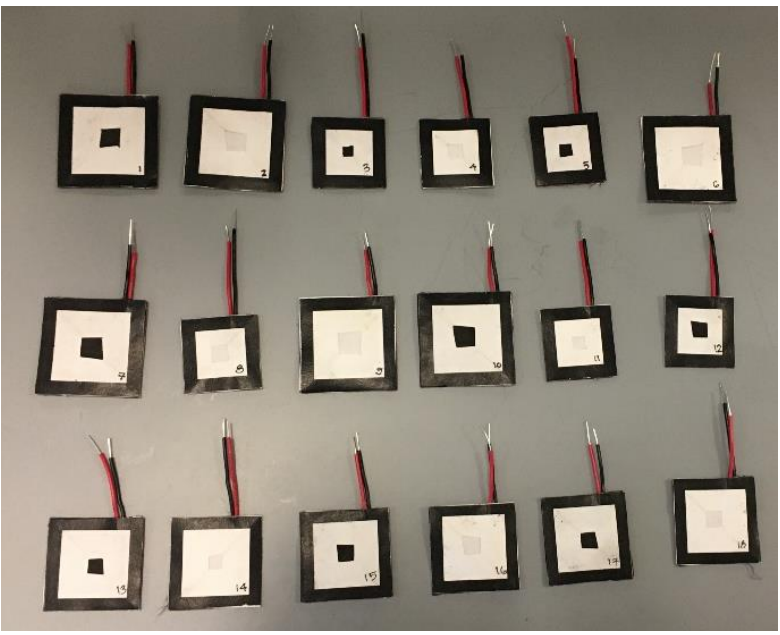

Figure 22: Completely Constructed PMFC's for Final Run

It should be noted that red leads were attached to the anode layer and black leads were attached to the cathode layer in order to prevent measurement mistakes. The stripped sections of the wires were what lay inside the PMFC, and the wires were held in place by the glued-together layers.

\subsubsection{Final Run Experimental Methods}

The final run tested each of the 18 PMFC's for 10 minutes each. Wastewater effluent was obtained roughly six and a half hours before testing began in order to ensure 
sample freshness. Three voltage data loggers with "grabber" probes were used to record the OCV's of the PMFC's, and for each PMFC, voltage was recorded every second after effluent was inserted. Recordings were uploaded via USB to EXCEL after testing was completed. For each PMFC, the OCV, time from sample, and voltage logger used were recorded. All tests were again performed inside a fume hood.

The order of the testing was randomized (see table 1) using a full 2 factor factorial with 3 replicates and 6 center points in Minitab. The first factor was size, which had three levels: (1) $33 \mathrm{~mm}$ by $33 \mathrm{~mm}$, represented by -1 in the Minitab chart; (2) $38 \mathrm{~mm}$ by 38 $\mathrm{mm}$ represented by 0 ; (3) $43 \mathrm{~mm}$ by $43 \mathrm{~mm}$, represented by 1 . The second factor was number of anode sides painted, which had two levels: (1) one side painted, represented by -1 in the Minitab output; (2) two sides painted, represented by 1 .

\begin{tabular}{|r|r|r|}
\hline Run Order & Size & Sides Painted \\
\hline 1 & 1 & -1 \\
\hline 2 & -1 & -1 \\
\hline 3 & 1 & -1 \\
\hline 4 & 1 & 1 \\
\hline 5 & 1 & -1 \\
\hline 6 & -1 & -1 \\
\hline 7 & 1 & 1 \\
\hline 8 & -1 & 1 \\
\hline 9 & -1 & 1 \\
\hline 10 & 1 & 1 \\
\hline 11 & -1 & -1 \\
\hline 12 & -1 & 1 \\
\hline 13 & 0 & 1 \\
\hline 14 & 0 & -1 \\
\hline 15 & 0 & 1 \\
\hline 16 & 0 & -1 \\
\hline 17 & 0 & 1 \\
\hline 18 & 0 & -1 \\
\hline & & \\
\hline & &
\end{tabular}

Table 1: Final Run's Randomized Trial with Center Points 
For each PMFC tested, OCV was measured between the anode and cathode. To measure $\mathrm{OCV}$, the $\mathrm{COM}$ side and ground side of the voltage meter were attached using the "grabber" probes to the cathode and anode leads respectively (see figure 23 below). Effluent was again placed in the middle cut-out of the insertion layer, and each PMFC received $5 \mathrm{ml}$ of effluent from a plastic dropper. Before each inoculation, the dropper was used to "stir" up the effluent in order to ensure even distribution of effluent and microbes throughout the experimental runs

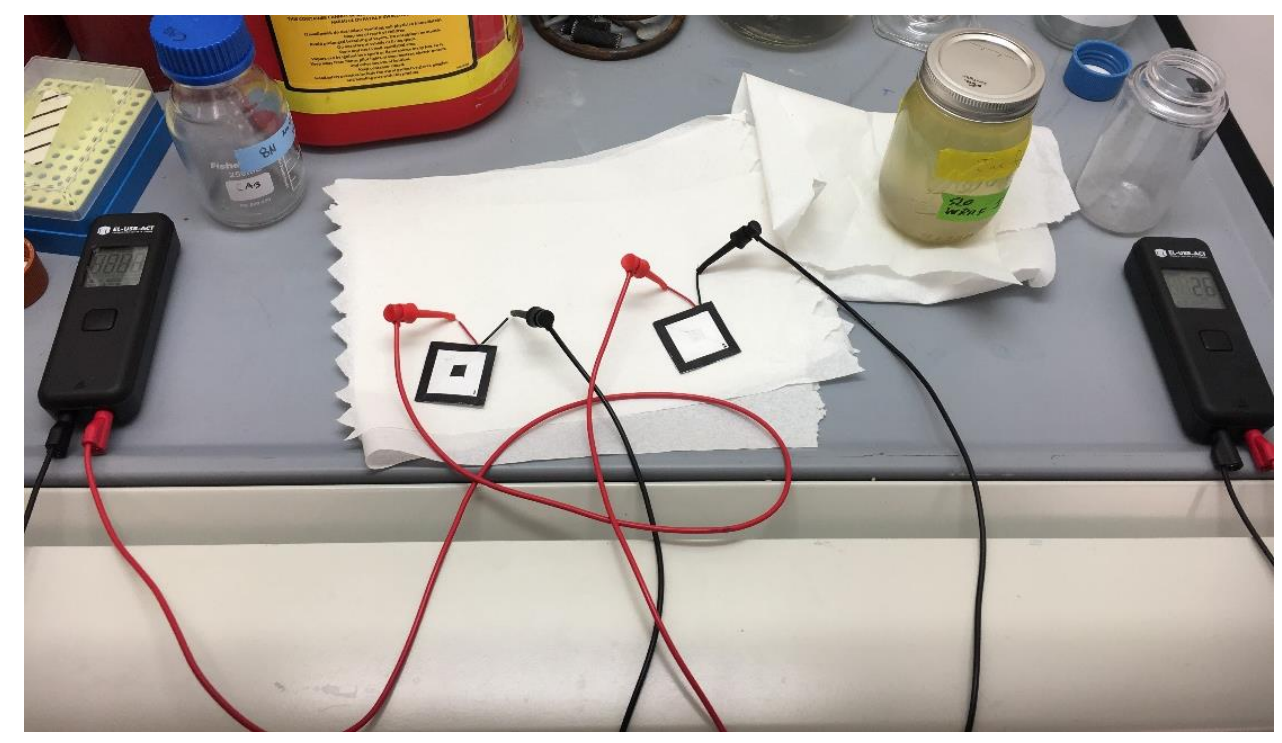

Figure 23: Experimental Setup for Final Run

It should be noted that the last two PMFC's used tap water instead of effluent in order to act as controls for this experiment. The controls served to confirm that the devices were working due to microbial activity, and were not simply the result of flux across the membranes. The reason that tap water was used instead of deionized water is that tap water is not deionized, just like wastewater effluent. 


\section{Chapter 3}

\section{RESULTS}

\subsection{Initial Run Results}

The results of the initial run were, as stated above, originally written by hand. These results were then transcribed into EXCEL and ultimately analyzed in Minitab. See Appendix A for a sample of the raw data.

\subsubsection{Initial Run Data Analysis}

The results were analyzed without the first PMFC's data, since the first PMFC had readings of 0 Volts and the measurement method was changed afterwards. With the first PMFC's data removed, an ANOVA was performed with time and CEM material as its factors. For all tests in both the initial and experimental runs, including Tukey comparisons and regressions, $\mathrm{p}=.05$ was used as the cutoff for significance. As seen in figure 24 below, CEM type was a significant factor, although there was no significant interaction between the two factors. Even though time did not meet the $\mathrm{p}=.05$ cutoff, it still appears to be significant because its p-value is so close to the cutoff.

\begin{tabular}{lrrrrrrr} 
Source & DF & Seq SS & Contribution & Adj SS & Adj MS & F-Value & P-Value \\
\hline PMFC & 2 & 25685 & $9.49 \%$ & 25685 & 12842 & 4.61 & 0.014 \\
Time (sec) & 10 & 55384 & $20.47 \%$ & 51282 & 5128 & 1.84 & 0.075 \\
PMFC*Time (sec) & 20 & 36173 & $13.37 \%$ & 36173 & 1809 & 0.65 & 0.857 \\
Error & 55 & 153363 & $56.67 \%$ & 153363 & 2788 & & \\
Total & 87 & 270604 & $100.00 \%$ & & & &
\end{tabular}

Figure 24: ANOVA Results for Initial Run

After running the ANOVA to determine significant factors, Tukey pairwise comparisons were run on the data in order to determine which levels of the factors produced significantly different results, i.e. which settings produced the highest voltage. 
As seen in figure 25, Nafion, represented by $\mathrm{N}$, has a significantly higher mean than the other two CEM materials.

\begin{tabular}{lrrrr} 
PMFC & N & Mean & \multicolumn{2}{l}{ Grouping } \\
\hline N & 33 & 86.4727 & A & \\
W & 22 & 54.1818 & A & B \\
F & 33 & 49.5152 & & B
\end{tabular}

Means that do not share a letter are significantly different.

Figure 25: Tukey Pairwise Comparisons for CEM Type

\begin{tabular}{lrrll}
$\begin{array}{l}\text { Time } \\
(\mathrm{sec})\end{array}$ & N & Mean & Grouping \\
\hline 30 & 8 & 108.222 & $\mathrm{~A}$ & \\
270 & 8 & 86.444 & $\mathrm{~A}$ & $\mathrm{~B}$ \\
180 & 8 & 68.000 & $\mathrm{~A}$ & $\mathrm{~B}$ \\
240 & 8 & 65.722 & $\mathrm{~A}$ & $\mathrm{~B}$ \\
90 & 8 & 64.389 & $\mathrm{~A}$ & $\mathrm{~B}$ \\
60 & 8 & 64.289 & $\mathrm{~A}$ & $\mathrm{~B}$ \\
120 & 8 & 62.333 & $\mathrm{~A}$ & $\mathrm{~B}$ \\
210 & 8 & 61.611 & $\mathrm{~A}$ & $\mathrm{~B}$ \\
150 & 8 & 58.167 & $\mathrm{~A}$ & $\mathrm{~B}$ \\
300 & 8 & 58.111 & $\mathrm{~A}$ & $\mathrm{~B}$ \\
0 & 8 & -0.000 & & $\mathrm{~B}$ \\
\multicolumn{5}{c}{ Means that do not share a letter are significantly different. }
\end{tabular}

Figure 26: Tukey Pairwise Comparisons for Time

While time was not nearly as significant as CEM, it was interesting to note from the above Tukey comparison that 30 seconds after effluent addition produced the highest mean voltage in the PMFC's. 


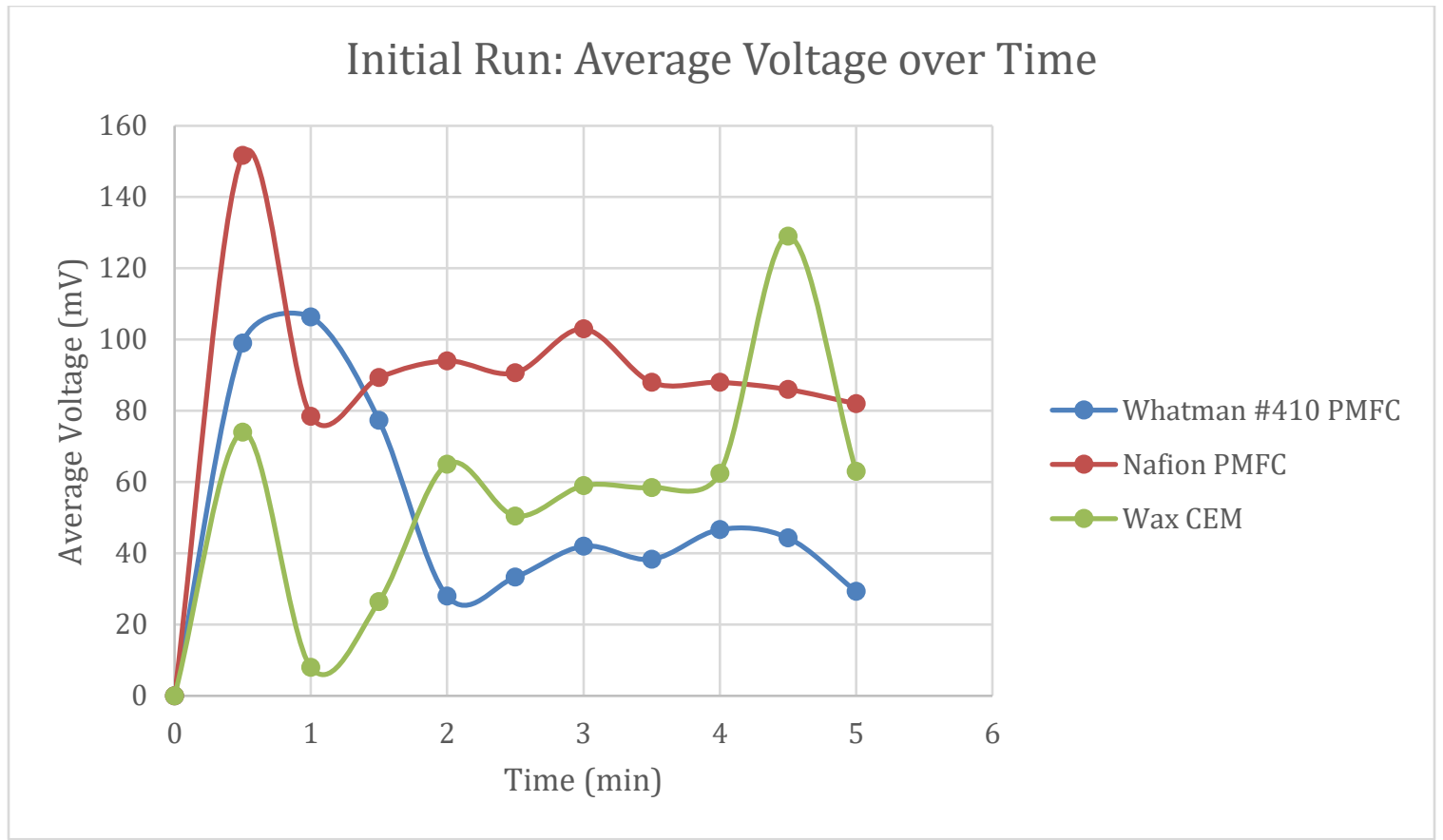

Figure 27: Voltage Over Time for Initial Run

Something interesting in figure 27 above is that while the PMFC's that used Nafion and Whatman Paper \#410 have an early voltage spike followed by a decline, the PMFC's with wax CEM's had an early spike followed by an increase in voltage. This initial spike in voltage is likely due to membrane potentials created by the initial flux of effluent through the device. Both the Whatman \#410 and Nafion CEM's reached a steady state after the initial spike in voltage, which is consistent with other MFC devices [11]. However, the wax CEM increased its voltage after the initial spike, which is not something usually seen in MFC's, and the reason for this increase was unknown.

\subsection{Final Run Results}

As stated above, the raw data was uploaded from the voltage data loggers to EXCEL via USB. Using the hand recorded start/stop times, the data was then parsed through in order to determine the start and stop times. For consistency, only 10 minutes 
of data were analyzed from each PMFC, even if it appeared that a PMFC had run for longer than 10 minutes. All data was again analyzed in Minitab.

\subsubsection{Final Run Data Analysis}

First, solely the data of the PMFC's that used effluent were analyzed, so that the results of the PMFC's that used water would not skew results. In addition, one of the PMFC's had had its leads fall out during testing, giving 0 Volt readings. Thus, this data was removed because it was a testing error and it would have skewed the data. As seen below in figure 28, a factorial regression was run which used time from when the sample was taken, usable area, and number of anode sides painted as factors. Usable area was defined as the surface area available for fluid exchange, i.e. the total surface area minus the area of printed wax. From the results of the regression, it is clear that time from sample, number of sides painted, and usable area all had significant effects on PMFC voltage.

\begin{tabular}{lr} 
Source & P-Value \\
\hline Model & 0.000 \\
Linear & 0.000 \\
Time from Sample $(\mathrm{sec})$ & 0.000 \\
sides painted & 0.000 \\
Usable Area (mm^2) & 0.000 \\
2-Way Interactions & 0.000 \\
Time from Sample $(\mathrm{sec})^{*}$ sides painted & 0.000 \\
Time from Sample $(\mathrm{sec})^{*}$ Usable Area (mm^2) & 0.001 \\
sides painted*Usable Area (mm^2) & 0.000 \\
3-Way Interactions & 0.000 \\
Time from Sample $(\mathrm{sec})^{*}$ sides painted*Usable Area (mm^2) & 0.000 \\
Error & \\
Lack-of-Fit & 0.000 \\
Pure Error & \\
Total &
\end{tabular}

Figure 28: Factorial Regression Results for Final Run 
Using the above factorial regression, main effects and interaction plots were created for all three factors in order to determine which settings would create the highest PMFC voltage. As can be seen in figure 29 below, the lower the time to sample, the higher the voltage. Also, it is clear that only painting one side of the anode produces a greater voltage than painting both sides. The greatest effect by far was that of usable area, which increased the voltage as the area was increased.

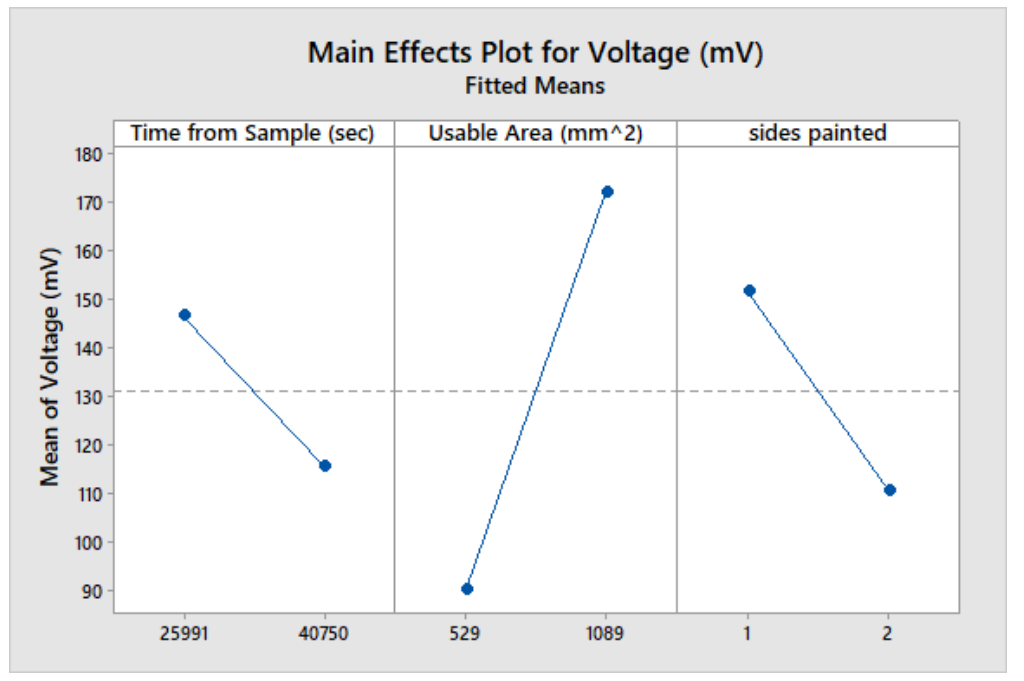

Figure 29: Main Effects Plot for Final Run

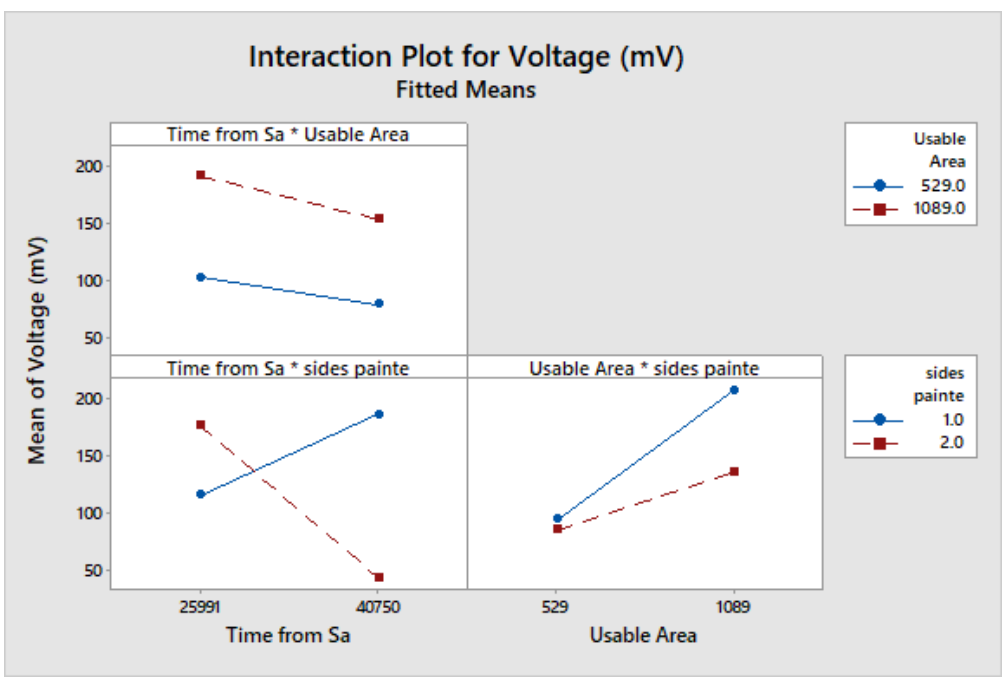

Figure 30: Interaction Effects Plot for Final Run 
While the interaction effects were significant in the regression, you can see in figure 30 above that there only appears to be major interaction between the time from sample and the number of anode sides painted. This mismatch between the interaction effects plot and the regression results is likely due to the fact that there are some significant factors that are not being taken into account in the factorial regression (which will have to be studied in the future). The voltages of the various PMFC configurations were also averaged and graphed over time, as seen in figure 31. It is interesting to note that while the main effects plot says that greater surface area increases voltage, the middle sized geometry with one anode painted actually achieved the highest voltages. The reason for this seeming paradox is likely that while the $38 \mathrm{~mm}$ by $38 \mathrm{~mm}, 1$ sided anode PMFC had a higher peak voltage, the $43 \mathrm{~mm}$ by $43 \mathrm{~mm}$ had the higher average voltage between the different configurations. Thus increasing size does indeed increase the voltage achieved by the PMFC. Note that the initial negative voltage of some PMFC's in the figure below is likely due to polarity reversals from fluid flux or substrate imbalances, as stated in the introduction [25]. 


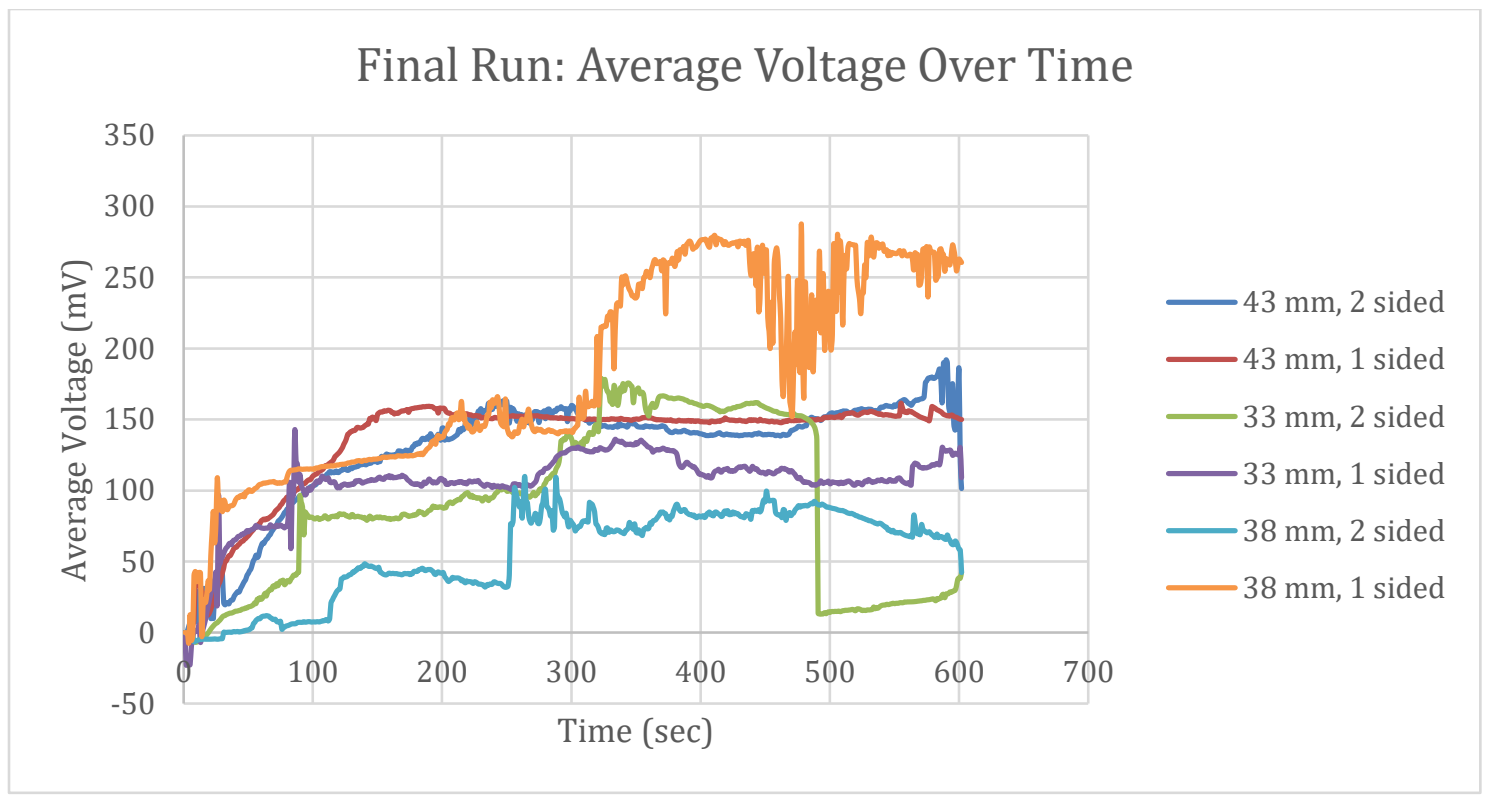

Figure 31: Average Voltage Over Time for Final Run

In addition to determining which PMFC setting produced the highest voltage, two controls were also run to determine if the devices really worked or not. Thus, an ANOVA was used, and it was revealed that the material used was indeed a significant factor, as seen in figure 32. Further analysis was performed using Tukey pairwise comparisons, which revealed that effluent did in fact produce a higher voltage than water (see figure $32)$.

\begin{tabular}{lrrrrrrr} 
Source & DF & Seq SS & Contribution & Adj SS & Adj MS & F-Value & P-Value \\
\hline Material & 1 & 47851806 & $28.20 \%$ & 47851806 & 47851806 & 4012.00 & 0.000 \\
Error & 10215 & 121836043 & $71.80 \%$ & 121836043 & 11927 & & \\
Total & 10216 & 169687849 & $100.00 \%$ & & & &
\end{tabular}

Figure 32: ANOVA for Materials in Final Run

\begin{tabular}{lrrr} 
Material & N & Mean & Grouping \\
\hline Effluent & 9015 & 131.669 & A \\
Water & 1202 & -80.741 & B
\end{tabular}

Means that do not share a letter are significantly different.

Figure 33: Tukey Pairwise Comparisons for Materials in Final Run 
In order to help determine how changing the size of the PMFC in the future could change the voltage achieved, I used the factorial regression to predict voltages for different dimensions (see table 2).

\begin{tabular}{|r|r|}
\hline $\begin{array}{l}\text { Usable Surface Area } \\
\left(\mathrm{mm}^{\wedge} 2\right)\end{array}$ & $\begin{array}{l}\text { Predicted Mean Voltage } \\
(\mathrm{mV})\end{array}$ \\
\hline 1500 & 470 \\
\hline 2000 & 117 \\
\hline 2500 & 1511 \\
\hline 3000 & 1859 \\
\hline 3500 & 2206 \\
\hline 4000 & 2553 \\
\hline 4500 & 2900 \\
\hline 5000 & \\
\hline
\end{tabular}

Table 2: Predictions for the Effect of Usable Surface Area on Voltage

The time from sampling was set to 0 seconds for all predictions in order to simulate using a fresh effluent sample for PMFC inoculation. In addition, the number of anode sides painted was set to 1 , since having 1 side painted produced the highest voltage. 


\section{Chapter 4}

\section{DISCUSSION}

\subsection{Conclusions}

\subsubsection{Initial Run Conclusions}

The aims of the initial run were to determine: (1) if the PMFC's were able to produce a measurable voltage; (2) to determine which CEM material produced the highest voltage. The first goal was clearly met, since all of the PMFC's produced a measurable voltage (except for the aforementioned first PMFC). The second goal was also met, since it was determined that Nafion was the CEM material that produced the highest voltage. This was why the final run only used Nafion as the CEM material.

\subsubsection{Final Run Conclusions}

The final run sought to determine: (1) if effluent would produce a higher voltage than the control (water); (2) if usable surface area had a significant effect on the voltage produced; (3) if time from sample had a significant effect on voltage; (4) if the number of anode sides painted had a significant effect on the voltage produced. The first goal was clearly met, since effluent produced a significantly greater voltage than water. The second aim was answered in that as surface area increases, so does voltage. The third goal was met, since clearly, the longer the time from sample, the lower the voltage produced by the PMFC. The final goal was fulfilled, since the main effects plots revealed that painting one side produced significantly more voltage than a double sided anode. Based on the above conclusions, it is clear that this kind of PMFC device has its voltage maximized when it has a large surface area, fresh effluent, and only one side of the anode painted. 
In addition, further goals of this study were to create an easier to construct and cheaper PMFC that was similar to the "origami" PMFC. The PMFC devices created for this thesis were undoubtedly easier to build than the "origami" PMFC because while my device only involved cutting, gluing, and painting, the model device used screen printing, binder solutions, carbon sprays, and a number of other time consuming techniques that were simply not necessary for my device. Furthermore, even without cost analysis, it is clear my devices are cheaper since they use less, and cheaper, materials. Thus, both the goal of an easy to construct and low cost device were met.

\subsection{Future Directions}

As stated above, the larger the surface area and the lower the time from sampling is, the higher the PMFC voltage achieved. Thus, an important future direction for these devices is to either increase the size of the PMFC in order to increase surface area, or to somehow change the geometry in order to maximize the internal surface area in some other way. In fact, from table 2 above, it is clear that to produce the highest theoretical possible voltage for an MFC ( 1.2 volts), future studies would only need to create a roughly 2" by 2" PMFC. Future experiments should also use effluent that is as fresh as possible in order to maximize the voltage achieved.

The conductivity of the anode surface is very important, so this aspect of the PMFC could be optimized in the future, since there are much more conductive materials than the graphite paint used in this paper. Another important aspect of future experiments would be to test the PMFC's using an autoclaved sample of wastewater in order to directly compare the "real" wastewater to a control without bacteria in order to validate the PMFC's functionality. In addition, from this study it is clear that the manufacturing 
process itself has an effect on the PMFC's performance, and thus aspects of the manufacturing process should also be optimized for device performance. Furthermore, the regression equation for the factorial was linear, however it was not investigated if there were any non-linear relationships in the regression. Thus, in the future further data analysis should be performed to investigate the true relationship of all the factors. Another future direction for this research is to use pure cultures of electrogenic bacteria (e.g. Shewanella oneidensis) as in the "origami" PMFC that this thesis is based on. This would allow for direct comparison of the performance of the PMFC's from this thesis and the "origami" PMFC's, which would allow us to determine the effect of using the less expensive materials and simpler construction methods of this study. 


\section{REFERENCES}

[1]- Chouler, Jon, et al. "A Screen-Printed Paper Microbial Fuel Cell Biosensor for Detection of Toxic Compounds in Water.” Biosensors and Bioelectronics, vol. 102, 2018, pp. 49-56., doi:10.1016/j.bios.2017.11.018.

[2]- Pereira, Luis Santos, et al. "Conceptual Thinking in Coping with Water Scarcity." Coping with Water Scarcity, 2009, pp. 77-98., doi:10.1007/978-1-4020-9579-5_5.

[3]- Connor, Richard. “The United Nations World Water Development Report 2015: Water for a Sustainable World." [4]- “Our Story.” Unicef Annual Report 2014, 2014, doi:10.30875/977ff2df-en. [5]- Bain, Robert et al. "Global assessment of exposure to faecal contamination through drinking water based on a systematic review." Tropical medicine \& international health : TM \& IH vol. 19,8 (2014): 917-27. doi:10.1111/tmi.12334.

[6]- Gada, Mihir. "Water Quality Tests.” NASA, NASA, www.grc.nasa.gov/www/k12/fenlewis/test.htm.

[7]- “Chapter A7. Section 7.0. Five-Day Biochemical Oxygen Demand.” 2003, doi:10.3133/twri09a7.0.

[8]-“A Screen-Printed Paper Microbial Fuel Cell Biosensor for Detection of Toxic Compounds in Water.” Biosensors and Bioelectronics, Elsevier, 3 Nov. 2017, www.sciencedirect.com/science/article/pii/S0956566317307364. [9]-“Fabrication and Characterization of Graphite-Cement Composites for Microbial Fuel Cells Applications.” Materials Research Bulletin, Pergamon, 30 Dec. 2016, www.sciencedirect.com/science/article/pii/S0025540816314489. 
[10]- Logan et. al. Microbial Fuel Cells: Methodology and Technology. web.mit.edu/pweigele/www/SoBEI/Info_files/Logan 2006 Environ Sci Technol.pdf. [11]- "Microbial Fuel Cells: From Fundamentals to Applications. A Review." Journal of Power Sources, Elsevier, 6 Apr. 2017, www.sciencedirect.com/science/article/pii/S0378775317304159. [12]- Bennetto, H. P. "Electricity generation by microorganisms." Biotechnology education 1.4 (1990): 163-168.

[13]- Kamitani, Ai, et al. "Microfabricated Microfluidic Fuel Cells." Sensors and Actuators B: Chemical, vol. 154, no. 2, 2011, pp. 174-180., doi:10.1016/j.snb.2009.11.014. [14]-“Challenges in the Application of Microbial Fuel Cells to Wastewater Treatment and Energy Production: A Mini Review.” Science of The Total Environment, Elsevier, 26 May 2018, www.sciencedirect.com/science/article/pii/S0048969718317777. [15]- Oh and Logan. "Voltage Reversal during Microbial Fuel Cell Stack Operation." Journal of Power Sources, vol. 167, no. 1, 2007, pp. 11-17., doi:10.1016/j.jpowsour.2007.02.016. [16]- “A Green Microbial Fuel Cell-Based Biosensor for In Situ Chromium (VI) Measurement in Electroplating Wastewater.” Medscape Log In. reference.medscape.com/medline/abstract/29076985. [17]-“A Green Microbial Fuel Cell-Based Biosensor for In Situ Chromium (VI) Measurement in Electroplating Wastewater.” Medscape Log In. reference.medscape.com/medline/abstract/29076985. 
[18]- Fraiwan, Arwa \& Choi, Seokheun. (2016). A Stackable, Two-chambered, PaperBased Microbial Fuel Cell. Biosensors and Bioelectronics. 83.

10.1016/j.bios.2016.04.025.

[19]- Fraiwan, Arwa, et al. “A Paper-Based Microbial Fuel Cell: Instant Battery for Disposable Diagnostic Devices.” Biosensors and Bioelectronics, vol. 49, 2013, pp. 410 414., doi:10.1016/j.bios.2013.06.001.

[20]-“Challenges in the Application of Microbial Fuel Cells to Wastewater Treatment and Energy Production: A Mini Review.” Science of The Total Environment, Elsevier, 26 May 2018, www.sciencedirect.com/science/article/pii/S0048969718317777.

[21]- "Powering Point-of-Care Diagnostic Devices." Biotechnology Advances, Elsevier, 26 Nov. 2015, www.sciencedirect.com/science/article/pii/S0734975015300549.

[22]- “A Disposable Power Source in Resource-Limited Environments: A Paper-Based Biobattery Generating Electricity from Wastewater.” Biosensors and Bioelectronics, Elsevier, 7 May 2016, www.sciencedirect.com/science/article/pii/S0956566316304432. [23]- Fraiwan, Arwa, and Seokheun Choi. "Bacteria-Powered Battery on Paper." Physical Chemistry Chemical Physics : PCCP, U.S. National Library of Medicine, 21 Dec. 2014, www.ncbi.nlm.nih.gov/pubmed/25363848.

[24]- Mohammadifar, M., et al. "Power-on-Paper: Origami-Inspired Fabrication of 3-D Microbial Fuel Cells.” Renewable Energy: An International Journal, vol. 118, Apr. 2018, pp. 695-700. EBSCOhost, doi:10.1016/j.renene.2017.11.059.

[25]-Dobrovl'skii et. al. "Proton-Exchange Membranes for Hydrogen-Air Fuel Cells." Russian Journal of General Chemistry, vol. 77, no. 4, pp. 766-777. 
[26]- P, Sergio. "Bare Conductive - Electric Paint (50ml).” COM, www.sparkfun.com/products/10994.

[27]- Bell, Terence. "What Makes Metals Conductive?" The Balance, The Balance, 22

Jan. 2019, www.thebalance.com/electrical-conductivity-in-metals-2340117. 


\section{APPENDIX A: SAMPLES OF RAW DATA}

Note: Full raw data available upon request.

\begin{tabular}{|l|r|r|r|}
\hline PMFC & Time $(\mathrm{sec})$ & Voltage $(\mathrm{mV})$ & \multicolumn{1}{|c|}{ RESI } \\
\hline F & 0 & 0.0 & 0.000 \\
\hline F & 30 & 70.0 & -29.000 \\
\hline F & 60 & 130.0 & 23.667 \\
\hline F & 90 & 100.0 & 22.667 \\
\hline F & 120 & 60.0 & 32.000 \\
\hline F & 150 & 70.0 & 36.667 \\
\hline F & 180 & 66.0 & 24.000 \\
\hline F & 210 & 65.0 & 26.667 \\
\hline F & 240 & 60.0 & 13.333 \\
\hline F & 270 & 70.0 & 25.667 \\
\hline N & 300 & 77.0 & 47.667 \\
\hline N & 0 & 0.0 & 0.000 \\
\hline N & 30 & 77.0 & -74.667 \\
\hline N & 60 & 20.0 & -58.533 \\
\hline N & 90 & 60.0 & -29.333 \\
\hline N & 120 & 60.0 & -34.000 \\
\hline N & 150 & 62.0 & -28.667 \\
\hline N & 180 & 84.0 & -19.000 \\
\hline N & 210 & 50.0 & -38.000 \\
\hline N & 240 & 50.0 & -38.000 \\
\hline N & 270 & 37.0 & -49.000 \\
\hline F & 300 & 31.0 & -51.000 \\
\hline F & 180 & 0.0 & 0.000 \\
\hline F & 210 & 203.0 & 104.000 \\
\hline F & 60 & 170.0 & 63.667 \\
\hline & 90 & 114.0 & 36.667 \\
\hline & 120 & 0.0 & -28.000 \\
\hline & 0.0 & -33.333 \\
\hline
\end{tabular}

Table 3: Sample of Initial Run Raw Data 


\begin{tabular}{|c|c|c|c|c|c|c|c|}
\hline Run & Meter & Time from Sample (sec) & Voltage $(\mathrm{mV})$ & Size $(\mathrm{mm})$ & sides painted & Usable Area $\left(\mathrm{mm}^{\wedge} 2\right)$ & Material \\
\hline 1 & 1 & 25991 & 1.200 & 43 & 2 & 961 & Effluent \\
\hline 1 & 1 & 25992 & 8.500 & 43 & 2 & 961 & Effluent \\
\hline 1 & 1 & 25993 & 17.600 & 43 & 2 & 961 & Effluent \\
\hline 1 & 1 & 25994 & 25.700 & 43 & 2 & 961 & Effluent \\
\hline 1 & 1 & 25995 & 32.100 & 43 & 2 & 961 & Effluent \\
\hline 1 & 1 & 25996 & 36.800 & 43 & 2 & 961 & Effluent \\
\hline 1 & 1 & 25997 & 40.400 & 43 & 2 & 961 & Effluent \\
\hline 1 & 1 & 25998 & 43.200 & 43 & 2 & 961 & Effluent \\
\hline 1 & 1 & 25999 & 40.900 & 43 & 2 & 961 & Effluent \\
\hline 1 & 1 & 26000 & 37.400 & 43 & 2 & 961 & Effluent \\
\hline 1 & 1 & 26001 & 70.100 & 43 & 2 & 961 & Effluent \\
\hline 1 & 1 & 26002 & 64.800 & 43 & 2 & 961 & Effluent \\
\hline 1 & 1 & 26003 & 33.300 & 43 & 2 & 961 & Effluent \\
\hline 1 & 1 & 26004 & 41.900 & 43 & 2 & 961 & Effluent \\
\hline 1 & 1 & 26005 & 46.200 & 43 & 2 & 961 & Effluent \\
\hline 1 & 1 & 26006 & 48.000 & 43 & 2 & 961 & Effluent \\
\hline 1 & 1 & 26007 & 49.900 & 43 & 2 & 961 & Effluent \\
\hline 1 & 1 & 26008 & 46.700 & 43 & 2 & 961 & Effluent \\
\hline 1 & 1 & 26009 & 48.900 & 43 & 2 & 961 & Effluent \\
\hline 1 & 1 & 26010 & 50.100 & 43 & 2 & 961 & Effluent \\
\hline 1 & 1 & 26011 & 51.100 & 43 & 2 & 961 & Effluent \\
\hline 1 & 1 & 26012 & 52.400 & 43 & 2 & 961 & Effluent \\
\hline 1 & 1 & 26013 & 54.000 & 43 & 2 & 961 & Effluent \\
\hline 1 & 1 & 26014 & 54.500 & 43 & 2 & 961 & Effluent \\
\hline 1 & 1 & 26015 & 56.100 & 43 & 2 & 961 & Effluent \\
\hline 1 & 1 & 26016 & 64.700 & 43 & 2 & 961 & Effluent \\
\hline 1 & 1 & 26017 & 66.800 & 43 & 2 & 961 & Effluent \\
\hline 1 & 1 & 26018 & 70.200 & 43 & 2 & 961 & Effluent \\
\hline 1 & 1 & 26019 & 70.800 & 43 & 2 & 961 & Effluent \\
\hline 1 & 1 & 26020 & 72.300 & 43 & 2 & 961 & Effluent \\
\hline 1 & 1 & 26021 & 73.500 & 43 & 2 & 961 & Effluent \\
\hline 1 & 1 & 26022 & 75.700 & 43 & 2 & 961 & Effluent \\
\hline 1 & 1 & 26023 & 76.400 & 43 & 2 & 961 & Effluent \\
\hline 1 & 1 & 26024 & 77.300 & 43 & 2 & 961 & Effluent \\
\hline 1 & 1 & 26025 & 81.300 & 43 & 2 & 961 & Effluent \\
\hline
\end{tabular}

Table 4: Sample of Final Run Raw Data 
APPENDIX B: ADDITIONAL DRAWING FILES
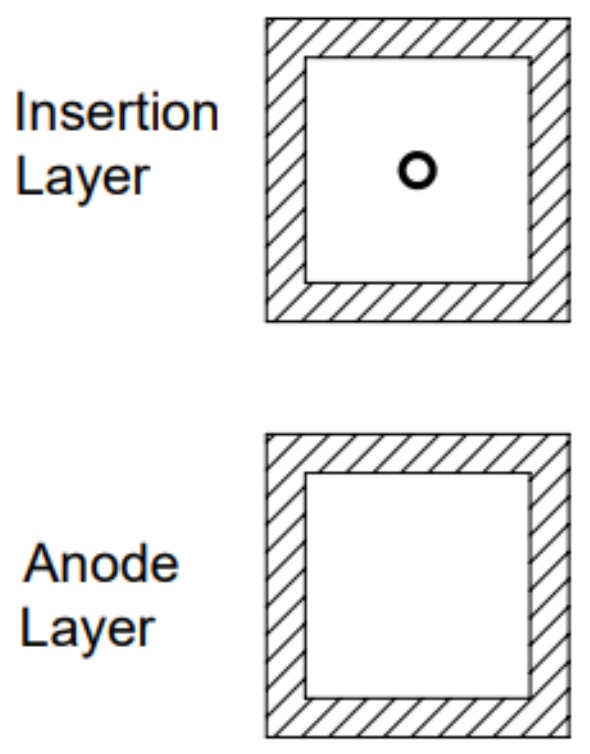

CEM

Layer

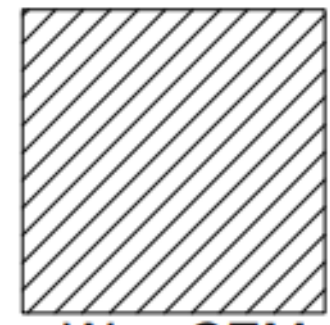

Wax CEM

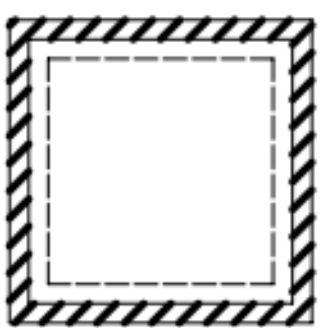

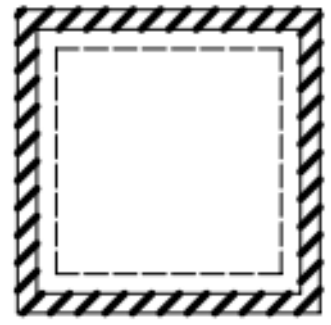

Nafion CEM

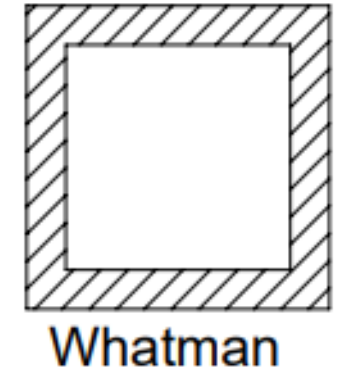

Paper \#410 CEM

Figure 34: Overall Layout for Initial PMFC 

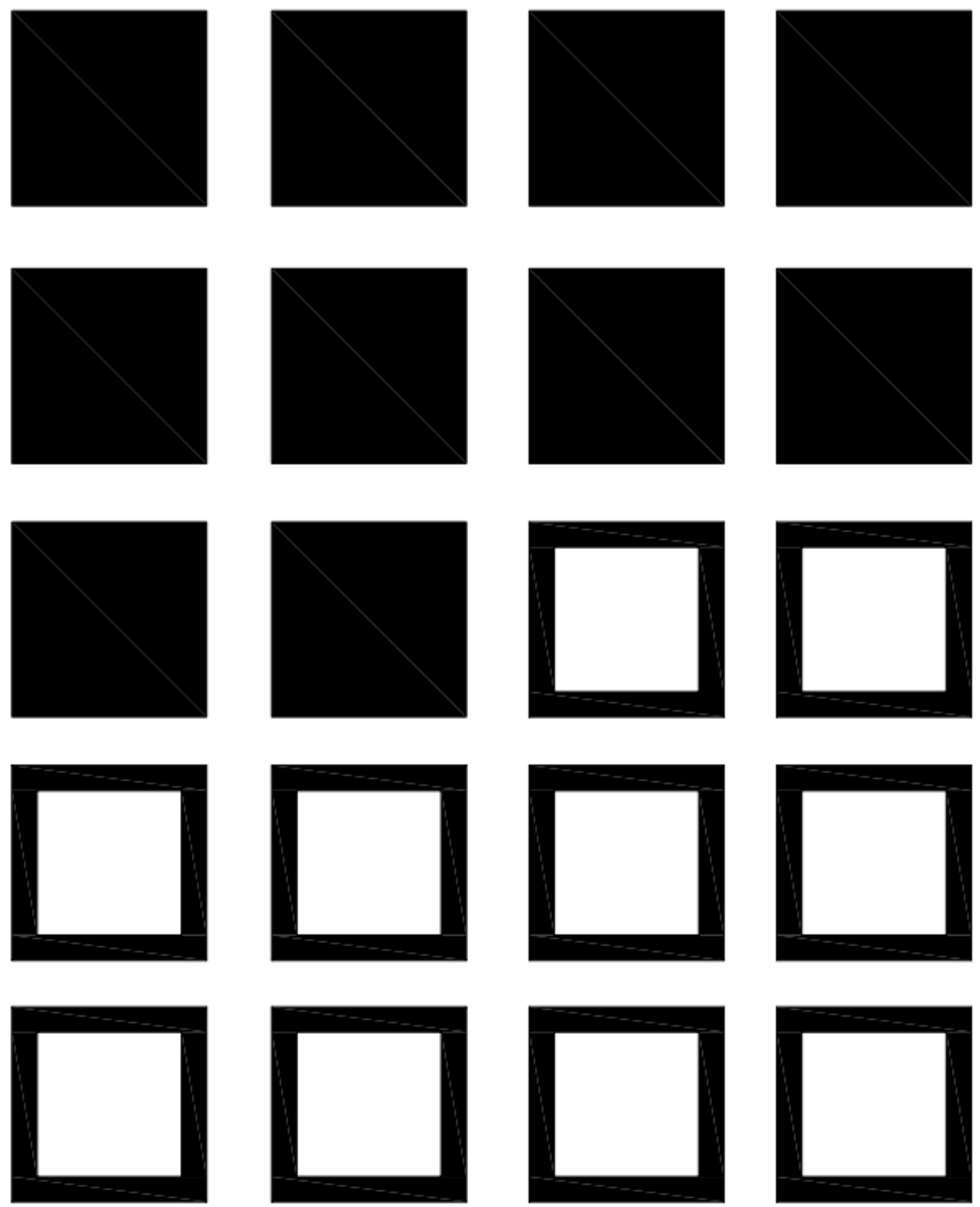

Figure 35: Initial Run Printing Layout 

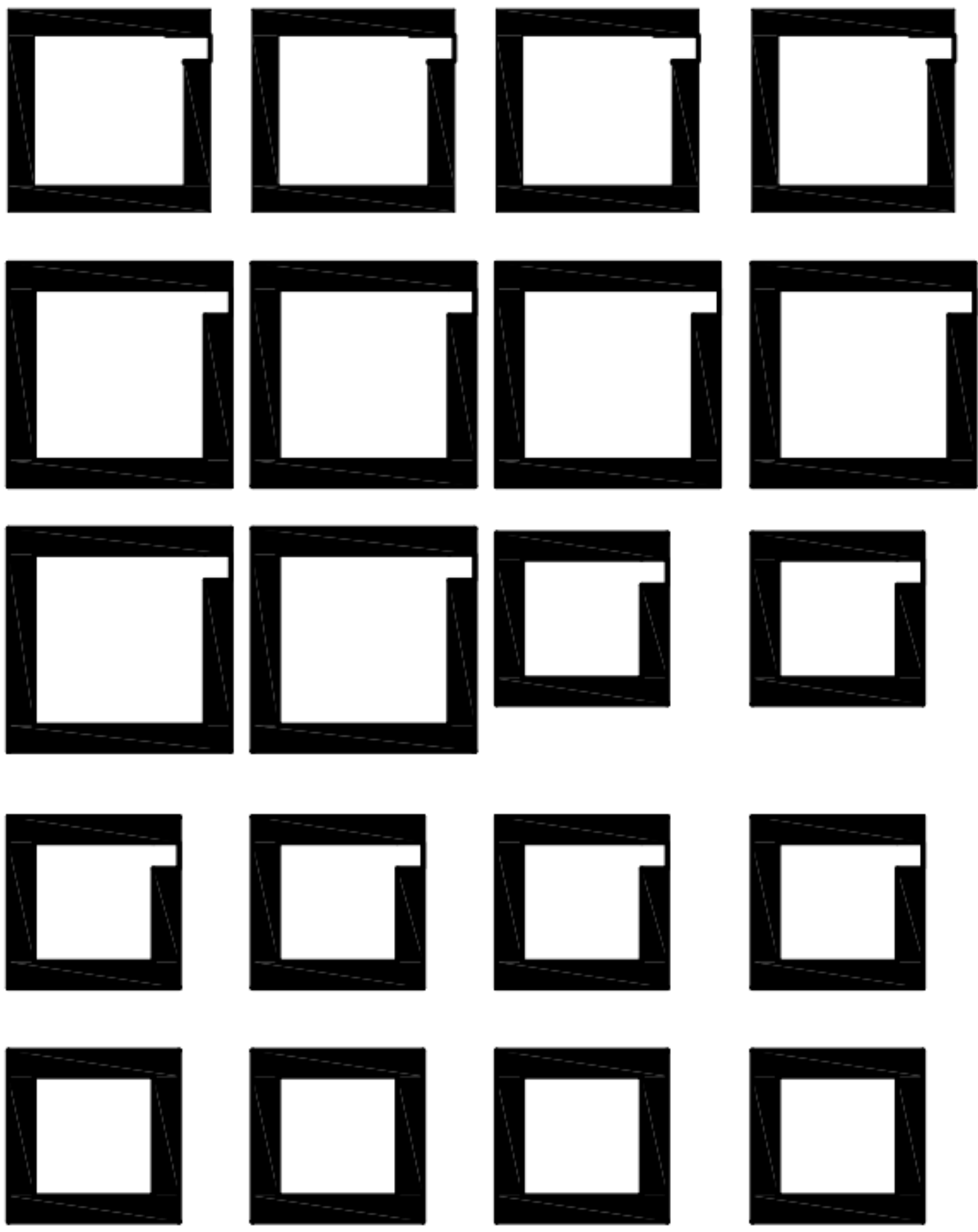

Figure 36: Final Run Printing Layout 
APPENDIX C: BILL OF MATERIALS

\begin{tabular}{|c|c|c|c|}
\hline Description & Value & $\begin{array}{l}\text { Total } \\
\text { Quantity }\end{array}$ & Source \\
\hline Whatman Paper \#1 & $\begin{array}{l}600 \mathrm{~mm} \times 600 \mathrm{~mm} \\
\text { sheet }\end{array}$ & 2 & https://www.fishersci.com \\
\hline Whatman Paper \#410 & $12.5 \mathrm{~cm}$ disk & 3 & https://www.southernlabware.com \\
\hline $\begin{array}{l}500 \text { Ohm, } 2 \text { Watt } \\
\text { Resistors }\end{array}$ & $500 \mathrm{Ohm}, 2 \mathrm{Watt}$ & 10 & https://www.digikey.com \\
\hline Nafion 115 & $30 \mathrm{~cm} \times 30 \mathrm{~cm}$ sheet & 1 & http://www.nafionstore.com \\
\hline Graphite Ink & $50 \mathrm{ml}$ bottle & 1 & https://www.bareconductive.com \\
\hline Glue Stick & $\mathrm{n} / \mathrm{a}$ & 1 & https://www.amazon.com \\
\hline Carbon Veil & $8.5 " x 11$ " sheet & 1 & http://www.tfpglobal.com \\
\hline Wire Spool Set & 25' long, $22 \mathrm{AWG}$ & 1 & https://www.adafruit.com \\
\hline
\end{tabular}

Table 5: Bill of Materials 